\title{
Microglial Cathepsin B Contributes to the Initiation of Peripheral Inflammation-Induced Chronic Pain
}

\author{
Li Sun, ${ }^{1 \star}$ Zhou Wu ${ }^{1 \star}$ Yoshinori Hayashi, ${ }^{1}$ Christoph Peters, ${ }^{2}$ Makoto Tsuda, ${ }^{3}$ Kazuhide Inoue, ${ }^{3,4}$ \\ and Hiroshi Nakanishi ${ }^{1,4}$ \\ ${ }^{1}$ Department of Aging Science and Pharmacology, Faculty of Dental Sciences, Kyushu University, Fukuoka 812-8582, Japan, ${ }^{2}$ Institute für Molekulare \\ Medizin und Zellforshung, Albert-Ludwings-Universität Freiburg, D-79104, Germany, ${ }^{3}$ Department of Molecular and System Pharmacology, Graduate \\ School of Pharmaceutical Sciences, Kyushu University, Fukuoka 812-8582, Japan, ${ }^{4}$ Japan Science and Technology Agency, Core Research for Evolutional \\ Science and Technology, 5, Sanbancho, Chiyoda-ku, Tokyo 102-0075, Japan
}

Interleukin (IL)-1 $\beta$ and IL-18 play critical roles in the induction of chronic pain hypersensitivity. Their inactive forms are activated by caspase-1. However, little is known about the mechanism underlying the activation of pro-caspase- 1 . There is increasing evidence that cathepsin B (CatB), a typical lysosomal cysteine protease, is involved in the pro-caspase-1 activation and the subsequent maturation of IL- $1 \beta$ and IL-18. In this context, CatB is considered to be an important molecular target to control chronic pain. However, no information is currently available about the role of CatB in chronic pain hypersensitivity. We herein show that CatB deficiency or the intrathecal administration of CA-074Me, a specific CatB inhibitor, significantly inhibited the induction of complete Freund's adjuvant-induced tactile allodynia in mice without affecting peripheral inflammation. In contrast, CatB deficiency did not affect the nerve injury-induced tactile allodynia. Furthermore, CatB deficiency or CA-074Me treatment significantly inhibited the maturation and secretion of IL- $1 \beta$ and IL-18 by cultured microglia following treatment with the neuroactive glycoprotein chromogranin A (CGA), but not with ATP. Moreover, the IL-1 $\beta$ expression in spinal microglia and the induction of tactile allodynia following the intrathecal administration of CGA depended on $\mathrm{CatB}$, whereas those induced by the intrathecal administration of ATP or lysophosphatidic acid were CatB independent. These results strongly suggest that CatB is an essential enzyme for the induction of chronic inflammatory pain through its activation of pro-caspase-1, which subsequently induces the maturation and secretion of IL- $1 \beta$ and IL-18 by spinal microglia. Therefore, CatB-specific inhibitors may represent a useful new strategy for treating inflammation-associated pain.

\section{Introduction}

Pain is an essential sense that allows an organism to avoid a dangerous environment, and helps promote wound healing, by helping the organism avoid any contact with pain-inducing stimuli. However, the increase in pain sensitivity can be long lasting, and may become pathological chronic pain after nerve injury (neuropathic pain) or in the case of inflammatory diseases, such as rheumatoid arthritis (inflammatory pain). Emerging data suggest that the hyperactivation of spinal microglia contributes to both neuropathic (Watkins et al., 2001; Tsuda et al., 2003, 2005; Scholz and Woolf, 2007) and inflammatory pain (Svensson et al., 2003; Raghavendra et al., 2004; Hua et al., 2005). Interleukin-1 $\beta$ (IL-1 $\beta$ ) is well accepted as a key pain-related molecule in both

Received Feb. 13, 2012; revised June 29, 2012; accepted June 29, 2012.

Author contributions: H.N. designed research; L.S., Z.W., and Y.H. performed research; L.S., Z.W., C.P., K.I., M.T., and H.N. analyzed data; L.S., Z.W., and H.N. wrote the paper.

This work was supported by Japan Science and Technology Agency, Core Research for Evolutional Science and Technology, and Grants-in-Aid from Ministry of Education, Culture, Sports, Science, and Technology, Japan.

${ }^{*}$ L.S. and Z.W. contributed equally to this work.

The authors declare no competing financial interests.

Correspondence should be addressed to Hiroshi Nakanishi, Department of Aging Science and Pharmacology,

Faculty of Dental Sciences, Kyushu University, Fukuoka 812-8582, Japan. E-mail: nakan@dent.kyushu-u.ac.jp.

DOI:10.1523/JNEUROSCI.0677-12.2012

Copyright $\odot 2012$ the authors $\quad 0270-6474 / 12 / 3211330-13 \$ 15.00 / 0$ neuropathic and inflammatory pain (Samad et al., 2001; Sweitzer et al., 2001; Kawasaki et al., 2008; Ren and Torres, 2009).

Increasing evidence suggests that different mechanisms underlie the proteolytic cleavage of pro-IL- $1 \beta$ in inflammatory and neuropathic pain. Furthermore, the consequences of the production of mature IL-1 $\beta$ (mIL-1 $\beta$ ) may also be different in these two types of chronic pain models. Caspase-1, an intracellular cysteine protease, is essential for the proteolytic processing of pro-IL- $1 \beta$ to its mature form in the development of complete Freund's adjuvant (CFA)-induced inflammatory pain (Samad et al., 2001). The resultant mIL-1 $\beta$ subsequently induces the expression of cyclooxygenase-2 (COX-2) in the spinal dorsal horn, leading to the release of prostaglandin $\mathrm{E}_{2}\left(\mathrm{PGE}_{2}\right)$, which is a key molecule involved in tactile allodynia and mechanical hyperalgesia in inflammatory pain (Samad et al., 2001; Lee et al., 2004; Vardeh et al., 2009). In contrast, matrix metalloproteinase subtypes, but not caspase-1, were suggested to be responsible for the proteolytic cleavage of pro-IL-1 $\beta$ (Kawasaki et al., 2008) in nerve injuryinduced neuropathic pain, and this did not involve the expression of COX-2 in the spinal dorsal horn (Broom et al., 2004).

Recently, cathepsin B (CatB; EC 3.4.22.1), a typical cysteine lysosomal protease, has been suggested to promote the processing and secretion of $\mathrm{mIL}-1 \beta$ through the activation of procaspase-1. Several lines of evidence suggest that leakage of CatB from the lysosomes to the cytoplasm triggers the activation of 
the NOD-like receptor (NLR) family pyrin domaincontaining 3 (NLRP3) inflammasome after phagocytosis of fibrillar amyloid- $\beta$ (A $\beta$ ) by microglia (Halle et al., 2008). The activated NLRP3 inflammasome then activates pro-caspase- 1 to promote the processing and secretion of the IL-1 family members, mIL-1 $\beta$ and mIL-18 (Halle et al., 2008; Stutz et al., 2009; Tschopp and Schroder, 2010). The NLRP3 inflammasome is known to consist of the NLR family member, NLRP3, the adaptor protein, ASC, and the effector protein, pro-caspase-1. However, other studies have suggested that CatB is directly involved in the proteolytic cleavage of pro-caspase- 1 and the subsequent processing of pro-IL-1 $\beta$ in the endosomal/lysosomal system (Schotte et al., 1998; Hentze et al., 2003; Terada et al., 2010). CatB has been demonstrated to be involved in the production of mIL$1 \beta$, which is a key pain-related molecule (Samad et al., 2001; Sweitzer et al., 2001; Kawasaki et al., 2008; Ren and Torres, 2009). We thus hypothesized that CatB is involved in the generation of chronic pain. To confirm this hypothesis, we examined the effects of genetic CatB deficiency and a specific CatB inhibitor on the pain behaviors and the processing of IL-1 family members using mouse models of inflammatory and neuropathic pain.

\section{Materials and Methods}

Animals. Heterozygous mice of C57BL/6 background were kept in a specific pathogen-free condition at Kyushu University Faculty of Dental Sciences. The selection of CatB-deficient ( $\mathrm{CatB}-/-$ ) mice from their littermates obtained by heterozygous coupling was performed by examining the template genomic DNA isolated from tail biopsies, using CatB-exon 4-specific PCR with primers of MCB11 ( $5^{\prime}$-GGTTGCGTTCGGTGAGG-3') and MCBGT (5'-AACAAGAGCCGCAGGAGC-3') (Koike et al., 2003; Sun et al., 2010). The heterozygous mice that were used as control animals in the present study showed no pathological phenotypes when examined by histological, immunocytochemical, and biochemical methods.

Construction of the pain model. All procedures were performed under the guidelines of Kyushu University. For the inflammatory pain model, 5 -week-old male wild-type $(+/+)$ mice and $\mathrm{CatB}-/-$ mice were injected with CFA (heat-killed Mycobacterium butyricum were well suspended in mineral oil, $10 \mathrm{mg} / \mathrm{ml}, 20 \mu \mathrm{l}$ ) into one of the footpads or saline (mineral oil, $20 \mu \mathrm{l}$ ) into the other footpads under enflurane $/ \mathrm{O}_{2}$. The paw diameter was measured using a micrometer caliper (ThermoFisher Scientific). For the neuropathic pain model, mice were anesthetized with sodium pentobarbital (50 mg/kg, i.p.). Sterile procedures were used throughout the surgery to prevent infection and to minimize the influence of inflammation. The back of each animal was shaved and cleaned with benzalkonium chloride. A $1 \mathrm{~cm}$ incision was made in the middle lumber region (L4-L5). The L5 transverse process was identified (Rigaud et al., 2008) and carefully removed with bone rongeurs. The L4 ventral ramus was carefully isolated and freed from the adjacent nerve, and then the L4 nerve was transected. Sham-operated mice were subjected to removal of the L5 transverse process. The incision was washed with saline and closed. Intrathecal administration was performed using a $25 \mu \mathrm{l}$ Hamilton syringe with a 30 gauge needle according to the methods described previously (Hayashi et al., 2011).

Drug administration. Wild-type mice were intrathecally (between the L4 and L5 vertebrae) administered CA-074Me ( $2 \mu \mathrm{M}, 20 \mu \mathrm{M}, 200 \mu \mathrm{M}$, and $5 \mu \mathrm{l}) 1 \mathrm{~h}$ before CFA injection into the hindpaw. Wild-type mice and CatB- / - mice were intrathecally administered between the L4 and L5 chromogranin A (CGA; $10 \mathrm{nM}, 5 \mu \mathrm{l})$, a neuroactive glycoprotein widely distributed in the secretory granules of neurons and endocrine tissues, ATP $(100 \mathrm{~nm}, 10 \mu \mathrm{l})$, or lysophosphatidic acid (LPA; $200 \mu \mathrm{M}, 5 \mu \mathrm{l})(n=$ 6) using a $30 \mathrm{G} \times 1 / 2$ inch needle under enflurane $/ \mathrm{O}_{2}$.

Measurement of mechanical and thermal hyperalgesia. Wild-type and $\mathrm{CatB}-1-$ mice were habituated to the testing environment for $3 \mathrm{~d}$. Mice were tested for mechanical hypersensitivity of the footpads from $1 \mathrm{~d}$ before until $14 \mathrm{~d}$ after CFA injection or L4 spinal nerve injury every day.
The room temperature remained stable at $23^{\circ} \mathrm{C}$. The mice were placed in an acrylic cylinder ( $6 \mathrm{~cm}$ diameter) with wire mesh floors and allowed to habituate to the environment for $1 \mathrm{~h}$ before testing.

Mechanical allodynia was assessed by measuring the paw-withdrawal threshold (PWT) using von Frey filaments (0.02-2.0 g; North Coast Medical), which were applied to the mid-plantar surface of the footpads six times (1-2 s each). The 50\% PWT values were calculated using the up-down method. The PWT was measured on both the right and the left paw for the intrathecal administration of CGA (10 nM, $5 \mu \mathrm{l})$, ATP (100 $\mathrm{nM}, 10 \mu \mathrm{l})$, or LPA $(200 \mu \mathrm{M}, 5 \mu \mathrm{l})$ with the wild-type and CatB $-/-$ mice, and the mean was calculated (Chaplan et al., 1994, Hayashi et al., 2011).

Thermal hyperalgesia was determined by measuring the latency in seconds of a withdrawal response to radiant heat applied to the center of the plantar surface of the hindpaw (Plantar text; Ugo Basile). Mice were placed on an elevated glass platform and allowed to habituate for $1 \mathrm{~h}$. The thermal stimulus with a radiant heat source (infrared intensity of 50) was applied three times on each paw, and consecutive applications of radiant heat were separated by at least $3 \mathrm{~min}$. A cutoff time of $15 \mathrm{~s}$ was imposed to prevent tissue damage. The latency of response for each hindpaw was defined as the average of the three trials. A decrease in withdrawal latency was defined as heat hyperalgesia (Hargreaves et al., 1988).

Motor activities. The motor activities of wild-type and CatB $-/-$ mice were measured using cylinder and rotarod tests. The cylinder and rotarod tests were conducted according to the methods previously described (Hayashi et al., 2008).

Immunohistochemistry. The sections of footpads were obtained from wild-type and $\mathrm{CatB}-/-$ mice obtained $3 \mathrm{~d}$ after intraplantar injection of CFA. Animals were anesthetized deeply with sodium pentobarbital (50 $\mathrm{mg} / \mathrm{kg}$, i.p.) and perfused intracardially with $20 \mathrm{ml}$ of PBS, pH 7.35, followed by $100 \mathrm{ml}$ of $4 \%$ (w/v) paraformaldehyde in phosphate buffer, $\mathrm{pH}$ 6.9. The sections were hydrated and treated with $0.3 \% \mathrm{H}_{2} \mathrm{O}_{2}$ in methanol, and then were treated with $10 \%$ normal donkey serum for $2 \mathrm{~h}$ at $24^{\circ} \mathrm{C}$. The sections were incubated with the rat anti-CD4 (1:500;Santa Cruz Biotechnology) and rat anti-CD11b (1:500; Serotec) antibodies in a humidified chamber overnight at $4^{\circ} \mathrm{C}$. After washing with cold PBS, the sections were incubated with biotinylated-anti-rat secondary antibodies (1:200; Jackson ImmunoResearch) for $2 \mathrm{~h}$, and finally with peroxidaseconjugated streptavidin (1:300; Dako) for $1 \mathrm{~min}$ at $24^{\circ} \mathrm{C}$. The peroxidase was developed using 3,30-diaminobenzidine (DAB substrate kit; Vector Laboratories.), and then it was counterstained with Mayer's hematoxylin. The number of the positive cells in the footpads was counted under a $20 \times$ objective lens ( 3 sections/mouse, $n=3$ ).

Double-immunofluorescent staining. The samples of the L4-L5 spinal cords or dorsal root ganglion (DRG; L4-L5) from wild-type and CatB $-/-$ mice were obtained $3 \mathrm{~d}$ after intraplantar injection of CFA, intrathecal injection of CGA (10 nM, $5 \mu \mathrm{l})$, ATP (100 nM, $10 \mu \mathrm{l})$, LPA $(200 \mu \mathrm{M}, 5 \mu \mathrm{l})$, or saline. The samples were cryoprotected for $2 \mathrm{~d}$ in $30 \%$ sucrose in PBS and then were embedded in an optimal cutting temperature compound (Sakura Finetechnical). Serial coronal frozen sections $(14 \mu \mathrm{m})$ of the samples for double-immunofluorescent staining were prepared as previously reported (Hayashi et al., 2008). The sections were then incubated with antibodies: rabbit anti-Ibal (1:1000; Wako Pure Chemicals ) with goat anti-CatB (1:100; Santa Cruz Biotechnology); rabbit anti-Ibal (1:1000) with goat anti-cleaved IL-1 $\beta$ (m118, 1:100;Santa Cruz Biotechnology), which recognizes only the cleaved IL- $1 \beta$ corresponding to mIL-1 $\beta$; rabbit anti-phospho-p38 MAPK (pp38, 1:100; Cell Signaling Technology) with rat anti-F4/80 (1:800; AbD Serotec); and mouse anti-NeuN (1:1000 Millipore Bioscience Research Reagents) with goat anti-COX-2 (1:100; Santa Cruz Biotechnology) or mouse antiNeuN (1:1000; Santa Cruz Biotechnology) with rabbit anti-CGA (1:500; $\mathrm{Abcam})$ at $4^{\circ} \mathrm{C}$ overnight. After washing them with PBS, the sections were incubated with donkey anti-rabbit Cy3 (1:500; Jackson ImmunoResearch) and donkey anti-goat Alexa 488 (1:500; Jackson ImmunoResearch), donkey anti-rat Cy3 (1:500; Jackson ImmunoResearch) and donkey anti-rabbit Alexa 488 (1:500; Jackson ImmunoResearch), and donkey anti-mouse Cy3 (1:500; Jackson ImmunoResearch) and donkey anti-goat Alexa 488 (1:500; Jackson ImmunoResearch) or donkey antimouse Cy3 (1:500; Jackson ImmunoResearch) and donkey anti-rabbit Alexa 488 (1:500; Jackson ImmunoResearch) at $4^{\circ} \mathrm{C}$ overnight. The sec- 


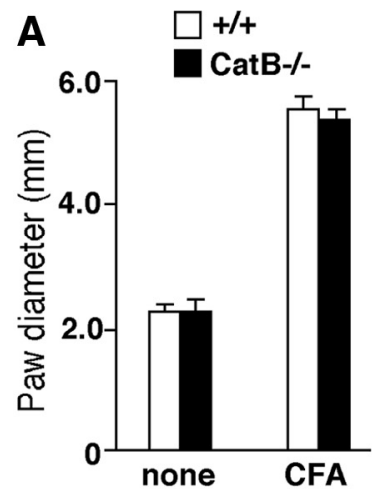

D

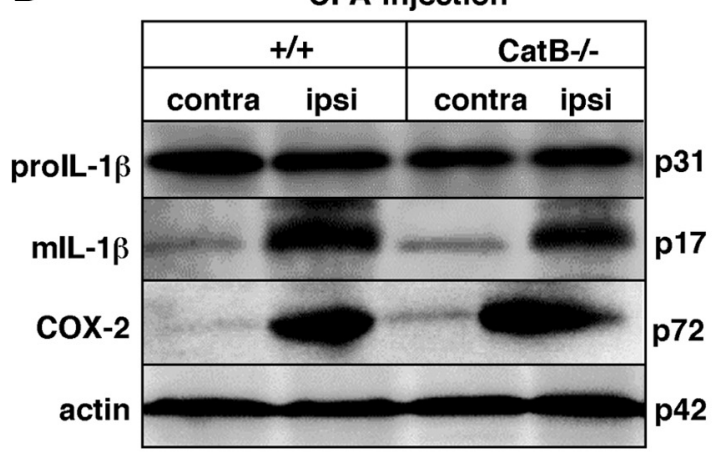

B

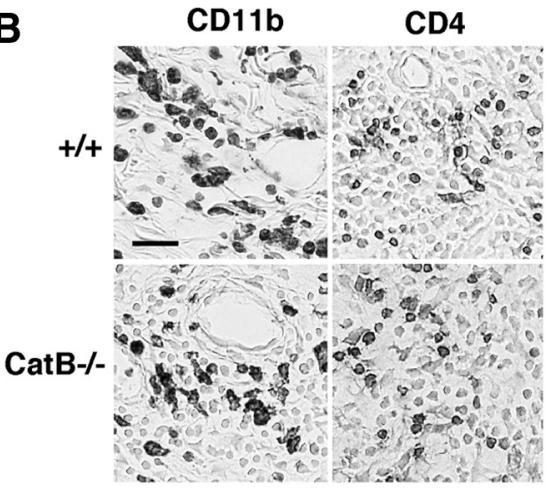

E
C

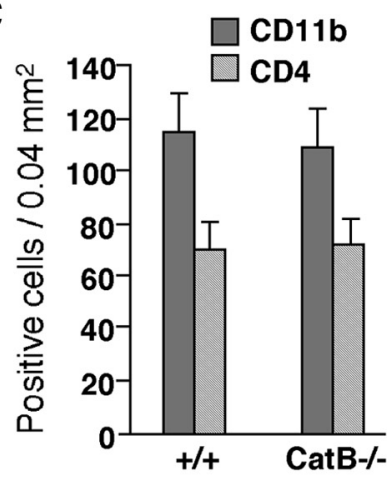

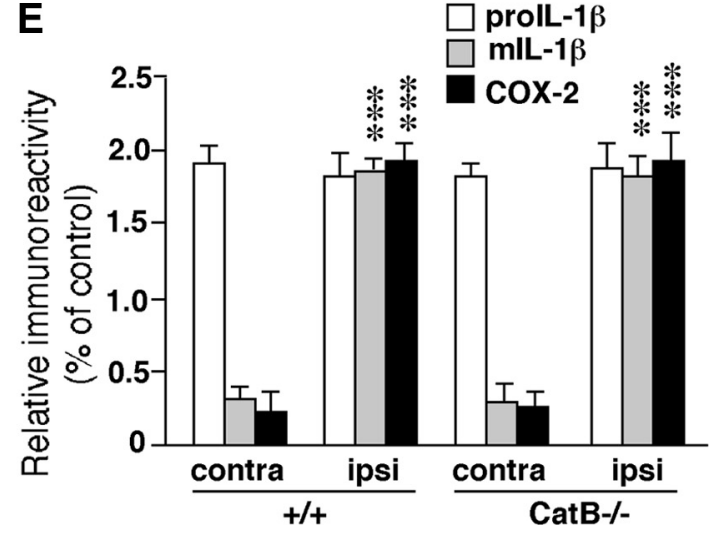

Figure 1. The peripheral inflammatory level in wild-type and CatB $-/-$ mice. $A$, The similar mean value of paw diameters was shown in the wild-type ( $+/+)$ and CatB $-/-$ mice at $3 \mathrm{~d}$ after CFA injection ( $10 \mathrm{mg} / \mathrm{ml}, 20 \mu \mathrm{l})$. $\boldsymbol{B}$, Infiltration of CD11b-positive macrophages and CD4-positive helper T-cells in the footpads of wild-type ( $+/+)$ and CatB $-/-$ mice at $3 \mathrm{~d}$ after CFA injection. Scale bar, $20 \mu \mathrm{m}$. $\boldsymbol{C}$, The mean number of CD11b- and CD4-positive cells infiltrated in the footpads at $3 \mathrm{~d}$ after CFA injection. Each column and bar represents the means \pm SEM ( $n=3$, each). $\boldsymbol{D}$, Immunoblots showing the expression of prolL- $1 \beta$, mIL-1 $\beta$, and COX-2 in the footpads of wild-type $(+/+)$ and CatB $-/-$ mice at $3 \mathrm{~d}$ after CFA injection. $\boldsymbol{E}$, The quantitative analyses of immunoblots in $\boldsymbol{D}$. Each column and bar represents the means \pm SEM $\left(n=3\right.$, each). ${ }^{* * *} p<0.001$, two-way ANOVA test (contralateral side vs ipsilateral side).

tions were mounted in the anti-fading medium, Vectashield (Vector Laboratories). The fluorescence images were observed using a confocal laser-scanning microscope (CLSM; LSM510META Carl Zeiss). The immunoflurorescence (IF) intensity of CGA in DRG neurons was measured as the average pixel intensity within NeuN-positive cells for CGA immunoreactivity.

Quantitative morphological analyses of microglia. Images were processed using the ImageJ software program (National Institutes of Health). Confocal $Z$ stuck images ( $63 \times$ objective fields) were captured from the L4 spinal dorsal horn. The measurements of the somata of spinal microglia were quantified after outlining them using the ImageJ software program. The morphological analyses of spinal microglia were performed on Z-projections of confocal images. Spinal microglial processes were traced and then reconstructed as single spinal microglial images using the plug-in Simple Neurite Tracer software program, and semi-automated tracing of dendrites in the 3D image data (Cardona et al., 2010), which were used to calculate the total length of spinal microglial processes. The topological skeletonized images of single spinal microglia were converted from a binarized image of spinal microglia using the skeletonize function.

Microglial cell culture. The c-myc-immortalized mouse microglial cell line, MG6 (KIREN Cell Bank), was maintained in DMEM containing $10 \%$ fetal bovine serum (ICN Biomedicals) supplemented with $100 \mu \mathrm{M}$ $\alpha$-mercaptoethanol, $10 \mu \mathrm{g} / \mathrm{ml}$ insulin, $100 \mu \mathrm{g} / \mathrm{ml}$ streptomycin, and 100 $\mathrm{U} / \mathrm{ml}$ penicillin (BD Falcon) (Takenouchi et al., 2005; Nakamichi et al., 2006). Primary cultured microglia were isolated from the mixed primary cell cultures from the cerebral cortex of 3-d-old wild-type or CatB-/mice according to the previously described methods (Sastradipura et al., 1998; Terada et al., 2010).

Electrophoresis and immunoblotting. MG6 and the primary cultured microglia were cultured at a density of $5 \times 10^{5}$ cells $/ \mathrm{ml}$. After treatment with $10 \mathrm{~nm}$ CGA for $24 \mathrm{~h}$ (Peptide Institute), $5 \mathrm{~mm}$ AT P (Sigma) for $2 \mathrm{~h}$ after being primed by LPS ( $100 \mathrm{ng} / \mathrm{ml}$ ) for $1 \mathrm{~h}$ (Sigma), or LPA $10 \mu \mathrm{M}$ for $24 \mathrm{~h}$ (Sigma) in the presence or absence of YVAD-fluoromethylketone (z-YVAD-fmk; Calbiochem) or CA-074Me (Peptide Institute) for $1 \mathrm{~h}$ before adding CGA, ATP, or LPA, the cytosolic and cell culture supernatants were collected at the various time points. The paw, spinal cord, and DRG tissues were harvested at $3 \mathrm{~d}$ after CFA or saline injection. The samples were electrophoresed in $15 \%, 7.5 \%$, or $12 \%$ SDSpolyacrylamide gels, and the proteins on SDS gels were transferred electrophoretically to nitrocellulose membranes. Following the blocking, the membranes were incubated at $4^{\circ} \mathrm{C}$ overnight under gentle agitation with each primary antibody: goat anti-IL-1 $\beta$ (R-20, 1:1000;Santa Cruz Biotechnology), which recognizes both pro and mature forms of IL- $1 \beta$; goat anti-cleaved IL- $1 \beta$ (m118, 1:1000;Santa Cruz Biotechnology), which recognizes only the cleaved IL- $1 \beta$ corresponding to mIL- $1 \beta$, rat anti-IL- 18 (1:1000; Medical Biological Laboratories), mouse anti-pro-IL-18 (1: 1000; Medical Biological Laboratories), anti-COX-2 (1:1000;Santa Cruz Biotechnology), goat anti-CatB (1:1000;Santa Cruz Biotechnology), rat anti-caspase-11(1:1000; Novus), rabbit anti-CGA (1:1000; Abcam), antiIba1 (1:1000; Abcam), or mouse anti-actin (1:1000; Abcam) antibody. After washing, the membranes were incubated with horseradish peroxidase-labeled anti-goat (1:1000; R \& D Systems); anti-rat (1:1000; Beckman Coulter); anti-mouse (1:1000; GE Healthcare); or anti-rabbit (1:1000; GE Healthcare) antibody for $2 \mathrm{~h}$ at $24^{\circ} \mathrm{C}$, then the protein bands were detected by an enhanced chemiluminescence detection system (ECK kit; GE Healthcare Pharmacia Biotech) using an image analyzer (LAS-1000; Fuji Photo Film).

NLRP3 knockdown with small interfering RNAs. MG6 microglia were seeded on 24 -well plates $\left(7 \times 10^{4}\right.$ cells/well $)$ in the standard MG6 culture medium DMEM (without antibiotics). After $12 \mathrm{~h}$, the cells were transfected with $30 \mathrm{~nm}$ small interfering RNA (siRNA) targeted to NLRP3 mRNA (Applied Biosystems) or with 30 nm negative control siRNA (Ap- 

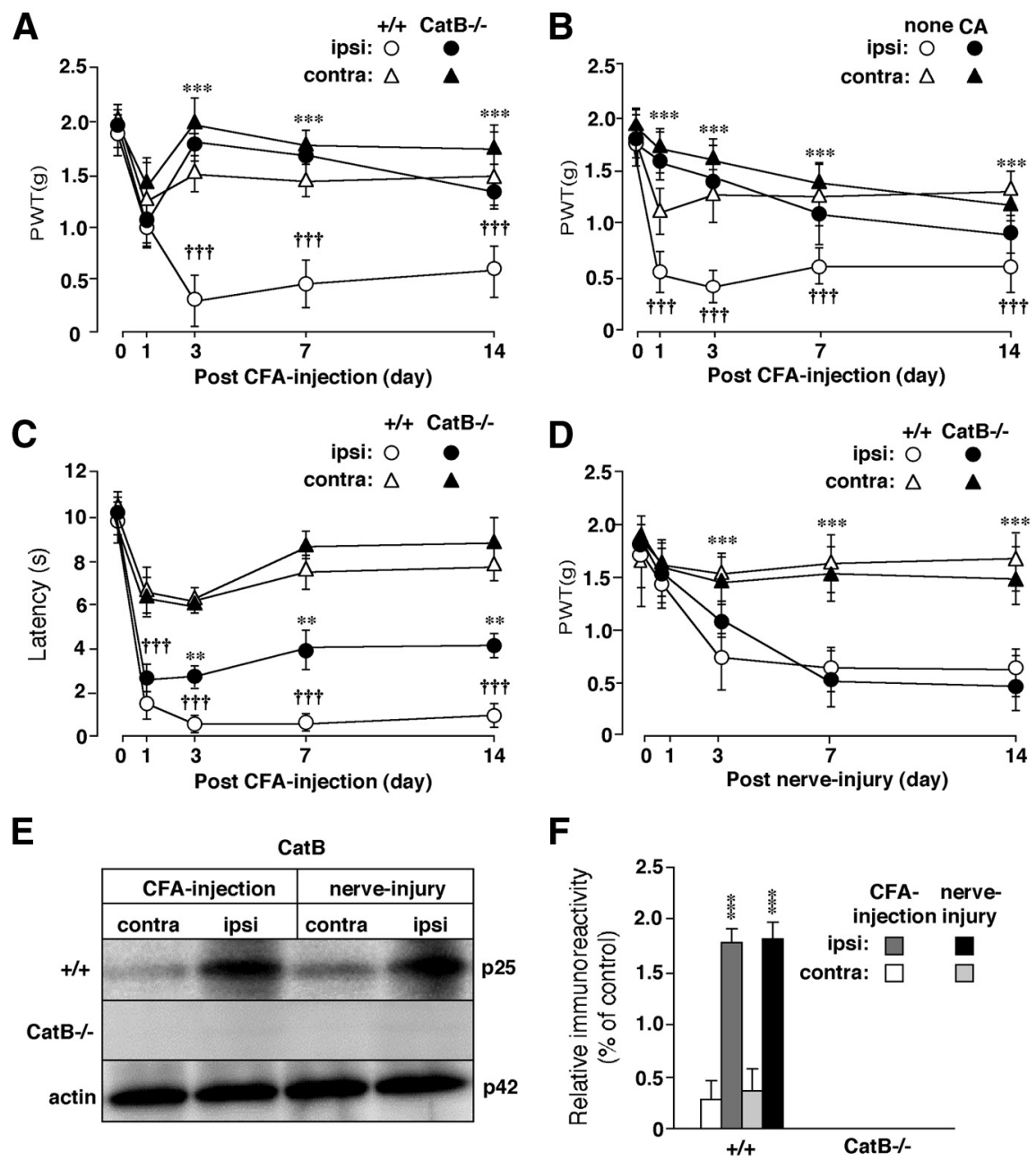

Figure 2. The effects of CatB deficiency on pain hypersensitivity. $A$, The inhibitory effects of CatB deficiency on CFA-induced tactile allodynia. $\boldsymbol{B}$, The inhibitory effects of intrathecal CA-074Me (CA, $200 \mu \mathrm{M})$ administration on CFA-induced tactile allodynia. $C$, The inhibitory effects of CatB deficiency on the CFA-induced thermal hyperalgesia. $D$, No significant effect of CatB deficiency on the nerve injury-induced tactile allodynia was observed. Each symbol and bar represents the means $\pm \operatorname{SEM}\left(n=6\right.$, each). ${ }^{* *} p<$ $0.01,{ }^{* * *} p<0.001$, two-way ANOVA test (contralateral side vs ipsilateral side); ${ }^{+t \dagger} p<0.001$, two-way ANOVA test (ipsilateral side of $+/+$ vs ipsilateral side of $(\mathrm{atB}-/-$ mice). $\boldsymbol{E}$, Immunoblots showing the expression of CatB in wild-type $(+/+)$ mice following CFA injection or nerve injury in the spinal dorsal horn, but not in CatB $-/-$ mice. $F$, The quantitative analyses of immunoblots in $\boldsymbol{E}$. Each column and bar represents the means \pm SEM $\left(n=3\right.$, each). ${ }^{* * *} p<0.001$, two-way ANOVA test (contralateral side vs ipsilateral side).

plied Biosystems), using the Lipofectamine RNAiMAX reagent (Invitrogen) according to the manufacturer's instructions. After $48 \mathrm{~h}$ of incubation with the siRNA, the cells were washed with PBS and incubated in serum-free DMEM with $10 \mathrm{~nm}$ CGA for $24 \mathrm{~h}$ or $1 \mathrm{~mm}$ ATP for $2 \mathrm{~h}$. MG6 microglia were primed with LPS $(100 \mathrm{ng} / \mathrm{ml})$ for $1 \mathrm{~h}$ before treatment with ATP. Finally, the cultured medium was collected and the amounts of IL- $1 \beta$ were measured using IL- $1 \beta$ ELISA kits (R \& D Systems). The absorbance at $450 \mathrm{~nm}$ was recorded using a microplate reader (Bio-Rad Laboratories).

Real-time quantitative RT-PCR analysis. The mRNA isolated from the cells treated with siRNA targeted to NLRP3 mRNA or the negative control was subjected to real-time quantitative RT-PCR. The total RNA from MG6 microglia was extracted with the Purelink RNA microkit (Invitrogen) according to the manufacturer's instructions. A total of $500 \mathrm{ng}$ of extracted total RNA was reverse transcribed to cDNA using the High Capacity RNA-to-cDNA Master Mix (Applied Biosystems). The thermal cycling was held at $50^{\circ} \mathrm{C}$ for $2 \mathrm{~min}$, and then at $95^{\circ} \mathrm{C}$ for $10 \mathrm{~min}$, followed by 40 cycles of $95^{\circ} \mathrm{C}$ for $15 \mathrm{~s}$ and $60^{\circ} \mathrm{C}$ for $1 \mathrm{~min}$. The cDNA was amplified in duplicate using TaqMan Universal PCR Master Mix (Applied Biosystems) with an Applied Biosystems 7500/7500 Fast Real-Time PCR Sys- tem. The data were evaluated using the 7500 software program (version 2.0; Applied Biosystems). The primer sequences used were as follows: NLRP3: 5'-UCUCAAGUCU AAGCACCAATT- $3^{\prime}$ and 5'-UUGGUGC UUAGACUUGAGAAG-3'. For data normalization, an endogenous control (actin) was assessed to control for the cDNA input and the relative units were calculated by a comparative $\mathrm{Ct}$ method. All real-time RT-PCR experiments were repeated three times, and the results are presented as the means of the ratios \pm SEM.

Fluorescence imaging of lysosomes and CatB. MG6 microglia were stained with the cellpermeable fluorescently labeled CatB substrate z-Arg-Arg-cresyl violet (CV-Cathepsin B Detection Kit; BIOMOL) or with Hoechst stain with $5 \mu \mathrm{M}$ acridine orange according to the manufacturer's instructions (CV-Cathepsin B Detection Kit AK-125; BIOMOL). The coverslips containing the stained live cells were then mounted in a drop of PBS and observed under a fluorescence microscope (Olympus BX-41).

Data analysis. The data are represented as the means \pm SEM. The statistical analyses were performed using a one- or two-way ANOVA with a post hoc Tukey's test using the GraphPad Prism software package. A value of $p<0.05$ was considered to indicate statistical significance (GraphPad Software).

\section{Results}

CatB deficiency reduces the CFAinduced long-lasting tactile allodynia We first explored whether CatB deficiency influences the nociceptive signaling using CFA-induced inflammatory and nerve injury-induced neuropathic models. Intraplantar injection of CFA $(20 \mu \mathrm{l})$ into the footpad produced an increase in paw diameter, and there were no significant differences in the mean paw diameter of wild-type and CatB-/- mice (Fig. $1 A$ ), which paralleled the comparable infiltration of inflammatory cells into the ipsilateral footpads in both genetic groups, detecting by CD11b-positive macrophages and CD4-positive helper T-cells (Fig. 1B,C). Infiltration of these cells was not observed in the hindpaw from naive animals of either wild-type or CatB-/mice (data not shown). Furthermore, CFA significantly increased the mean protein levels of mIL- $1 \beta$ and COX-2 in the ipsilateral paw in both genetic groups (Fig. $1 D, E$ ). The mean protein level of mIL- $1 \beta$ in the hindpaw from naive animals of both genetic groups was very low and comparable to that in the contralateral side of CFA-injected animals. There was no significant difference in the mean protein level of mIL- $1 \beta$ in the hindpaw of both genetic groups (data not shown), indicating that CatB deficiency did not influence basic expression of mIL-1 $\beta$ in the hindpaw. These observations strongly suggest that CatB deficiency does not affect the CFA-induced inflammation at the peripheral level. On the other hand, CatB deficiency significantly attenuated the CFA-induced pain behaviors. It was observed that CFA injection caused long-lasting tactile allodynia from $3 \mathrm{~d}$ after the injection in wild-type mice. In contrast, 

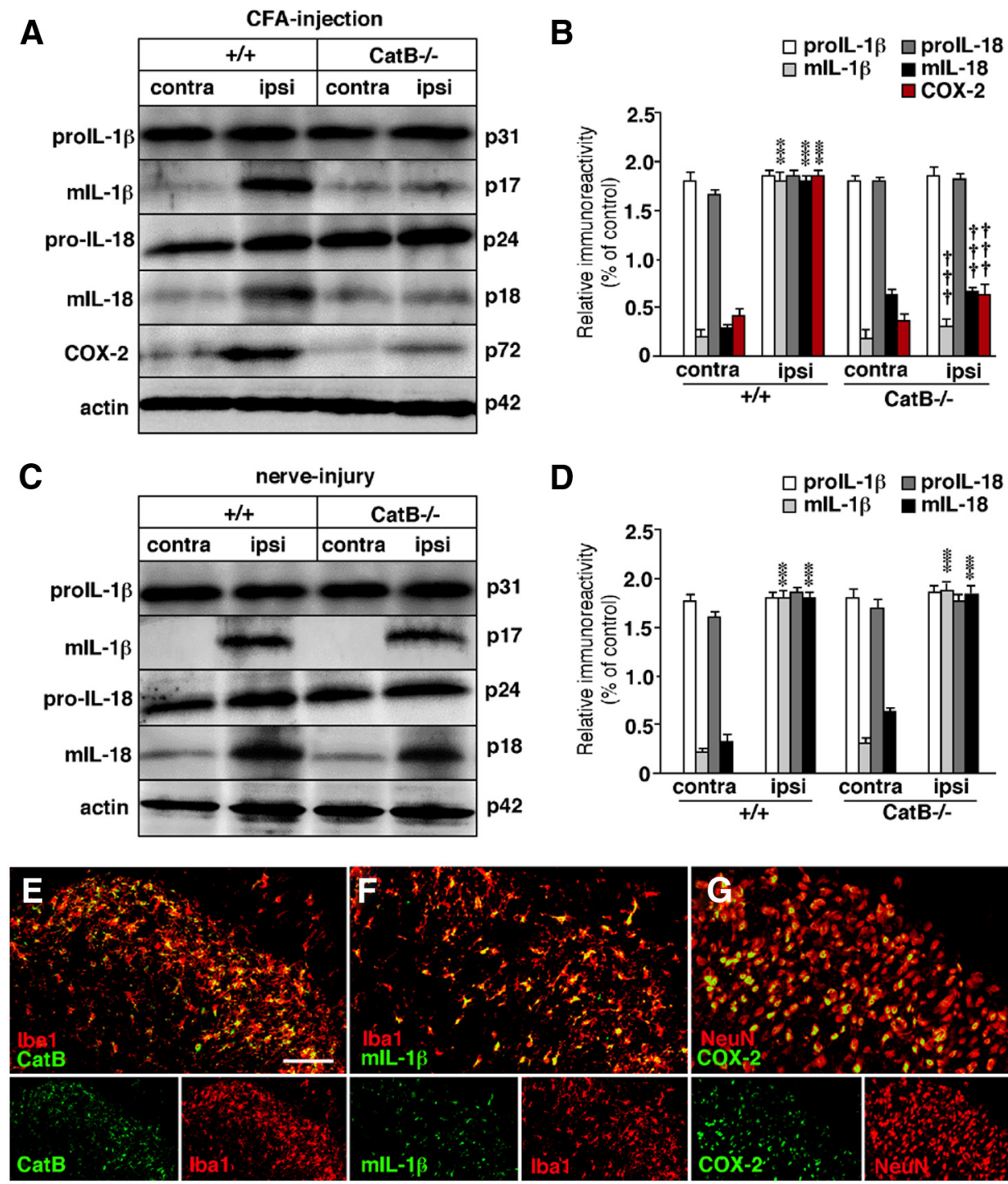

Figure 3. The differential requirements for CatB during the production of $\mathrm{mlL}-1 \beta$ and $\mathrm{mlL}-18$ in spinal dorsal horn after CFA injection or nerve injury. $A$, The immunoblot showing the expression of prolL-1 $\beta$, mlL-1 $\beta$, proll-18, mIL-18, and COX-2 in the spinal dorsal horn of wild-type $(+/+)$ and CatB- $/-$ mice at day 3 after CFA injection $(10 \mathrm{mg} / \mathrm{ml}, 20 \mu \mathrm{l})$. $\boldsymbol{B}$, The quantitative analyses of immunoblots in $A$. Each column and bar represents the means \pm SEM $\left(n=3\right.$, each). ${ }^{* * *} p<0.001$, two-way ANOVA test (contralateral side vs ipsilateral side); ${ }^{+t+} p<0.001$, two-way ANOVA (ipsilateral side of $+/+$ vs ipsilateral side of (atB $-/-$ mice). C, Immunoblot showing the expression of proll-1 $\beta$, mlL-1 $\beta$, pro-IL-18, and mIL-18 in the spinal dorsal horn of wild-type ( $+/+$ ) and CatB $-/-$ mice at day 3 after nerve injury. $\boldsymbol{D}$, The quantitative analyses of immunoblots in C. Each column and bar represents the means \pm SEM $\left(n=3\right.$, each). ${ }^{* * *} p<0.001$, two-way ANOVA test (ipsilateral side vs contralateral side). $\boldsymbol{E}-\boldsymbol{G}$, The IF CLSM images and the merged images for Iba1 (red) and CatB (green) (E), Iba1 (red) and mlL-1 $\beta$ (green) (F), NeuN (red), and COX-2 (green) (G) in the spinal dorsal horn of wild-type mice at day 3 after CFA injection. Scale bar, $50 \mu \mathrm{m}$.

CatB deficiency significantly attenuated the CFA-induced tactile allodynia (Fig. 2A). To examine the effect of pharmacological blockade of CatB activity on CFA-induced tactile allodynia, CA-074Me, a specific inhibitor of CatB, was intrathecally administered in wild-type mice. A single intrathecal administration of CA-074Me significantly attenuated CFAinduced tactile allodynia with the concentration of $200 \mu \mathrm{M}$ (Fig. $2 B$ ), but not by the concentration of either $2 \mu \mathrm{M}$ or $20 \mu \mathrm{M}$ (data not shown). Intrathecal administration of $200 \mu \mathrm{M} \mathrm{CA}-074 \mathrm{Me}(5$ $\mu \mathrm{l})$ may be diluted to the final concentration of $\sim 50 \mu \mathrm{M}$ before reaching the spinal dorsal horn, because the volume of the CSF in mice is estimated to be $\sim 20 \mu \mathrm{l}$. Therefore, intrathecal administration of $200 \mu \mathrm{M} \mathrm{CA}-074 \mathrm{Me}(5 \mu \mathrm{l})$ inhibited the CFA-induced tactile allodynia through inhibition of enzymatic activity of CatB without significant unspecific effects. Of note, neither the CatB deficiency nor the intrathecal injection of CA-074Me with the concentration of $200 \mu \mathrm{M}$ showed any motor disturbances when they were examined using the cylinder and rotarod tests (data not shown). Furthermore, CatB deficiency significantly attenuated the CFA-induced thermal hyperalgesia (Fig. 2C). In contrast, CatB deficiency had no significant effect on the nerve injury-induced tactile allodynia (Fig. 2D). It was also noted that sham-operated mice did not show the reduction of PWT (data not shown). These results were surprising, because the protein levels of CatB in the ipsilateral spinal dorsal horn were significantly increased in both pain models (Fig. 2E, F). It was also noted that there was no clear band corresponding to $\mathrm{CatB}$ in the spinal dorsal horn of $\mathrm{CatB}-/-$ mice (Fig. 2E,F). These results further suggest that CatB is involved in CFA-induced inflammatory pain, but not in the nerve injuryinduced neuropathic pain at the spinal cord level. 
A
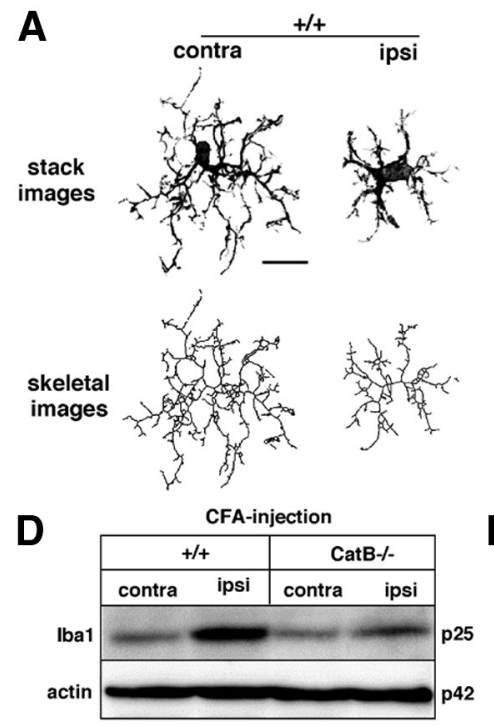

E

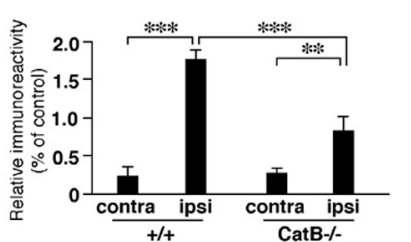

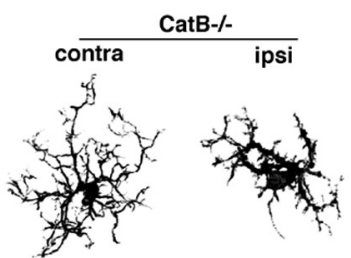

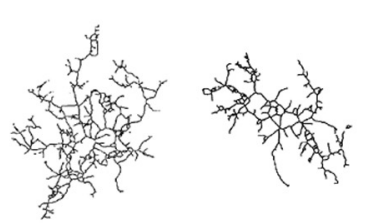

F

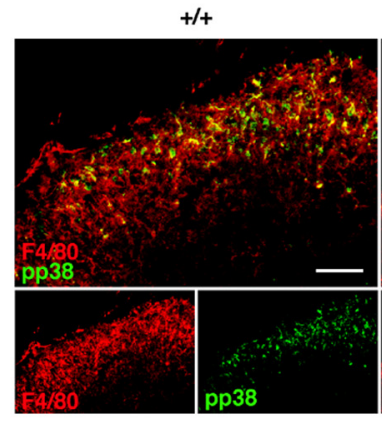

B

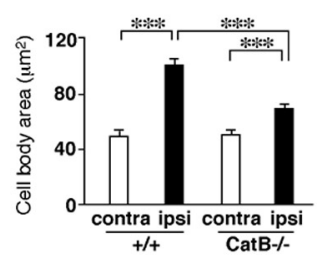

C

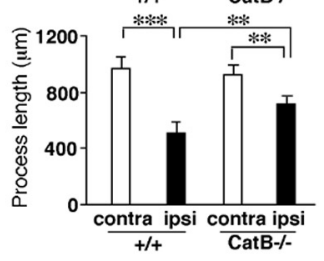

CatB-\%

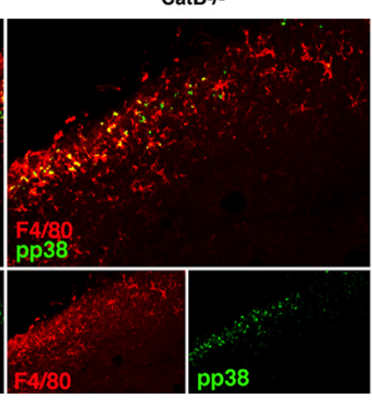

Figure 4. The morphological analyses of spinal microglia in the spinal dorsal horn of wild-type and CatB - / - mice at 3 d after CFA injection. $A, 2 D$-stack images of single spinal microglia were traced from CLSM images of Iba1-positive microglia in the contralateral and ipsilateral spinal dorsal horn of wild-type (left column) and CatB - / - mice (right column). The skeletal images showing the topological staining skeletonized were reconstructed from 2D-stack images of single spinal microglia. Scale bar, $10 \mu \mathrm{m}$. $\boldsymbol{B}$, The mean size of microglial cell bodies in wild-type $(+/+)$ and CatB $-/-$ mice subjected to CFA injection. Each column and vertical bar represents the mean \pm SEM ( $n=60-75$ cells from 4 animals). The asterisks indicate statistically significant differences between values ( ${ }^{* * *} p<0.001$, two-way ANOVA test). $C$, The mean length of microglial process in CFA-treated wild-type $(+/+)$ and CatB $-/-$ mice subjected to CFA injection. Each column and vertical bar represents the mean \pm SEM ( $n=50-65$ cells from 4 mice). The asterisks indicate a statistically significant difference between the values $\left({ }^{* *} p<0.01\right.$, ${ }^{* * *} p<0.001$, two-way AN0VA test). $\boldsymbol{D}$, The immunoblot showing lba1 expression in the spinal dorsal horn of wild-type $(+/+)$ and $C$ atB $-/-$ mice after $C F A$ injection. $\boldsymbol{E}$, The quantitative analyses of immunoblots in $\boldsymbol{C}$. Each column and vertical bar represents the means \pm SEM ( $n=3$, each). The asterisks indicate statistically significant differences between values $\left({ }^{* * *} p<0.001\right.$, two-way ANOVA test). $\boldsymbol{F}$, The IM CLSM images for F4/80 (red) and pp38 (green) in the spinal dorsal horn of the wild-type $(+/+$ ) mice and (atB $-/-$ mice at $3 \mathrm{~d}$ after CFA injection. Scale bar, $50 \mu \mathrm{m}$.

CatB deficiency reduces the CFA-induced production of IL-1 family members in hyperactivated spinal microglia

Although IL- $1 \beta$ has been demonstrated to be a key pain-related molecule in both pain models (Samad et al., 2001; Sweitzer et al., 2001; Kawasaki et al., 2008; Ren and Torres, 2009), increasing evidence suggests that there are CatB-dependent and CatBindependent mechanisms responsible for the production of mIL1- $\beta$ by microglia/macrophages (Halle et al., 2008; Terada et al., 2010). To address the question why CatB plays a pivotal role in the induction of CFA-induced inflammatory pain but not in the nerve injury-induced neuropathic pain, we examined the possibility that CatB deficiency affects the production of mIL-1 $\beta$ in spinal microglia following CFA injection, but not after the nerve injury. In wild-type mice, the mean protein levels of mIL- $1 \beta$ and mIL-18 but not pro-IL- $1 \beta$ and pro-IL-18 in the ipsilateral spinal dorsal horn were significantly increased at $3 \mathrm{~d}$ after CFA injection (Fig. $3 A, B$ ). The mean protein level of COX-2, which is a key enzyme required for prostaglandin $\mathrm{E}_{2}$ production during inflammatory states, was also significantly increased in the ipsilateral spinal dorsal horn of wild-type mice after CFA injection (Fig. $3 A, B$ ). On the other hand, the mean protein levels of mIL-1 $\beta$, mIL-18, and their inactive forms were not changed in the ipsilateral spinal dorsal horn of $\mathrm{CatB}-/-$ mice even after CFA injection (Fig. $3 A, B$ ). The mean protein level of COX-2 was increased in the ipsilateral spinal dorsal horn of CatB-/- mice after CFA injection, but the difference did not reach a statistical significance (Fig. $3 A, B$ ). The mean protein lev- els of mIL-1 $\beta$ and IL-18 in the spinal dorsal horn from naive animals of both genetic groups were very low and comparable to those in the contralateral side of CFA-injected animals. There was no significant difference of the mean protein levels of either mIL- $1 \beta$ or IL-18 in the spinal dorsal horn of both genetic groups (data not shown), indicating that CatB deficiency did not influence the basic expression of mIL- $1 \beta$ and mIL-18 in the spinal dorsal horn. In contrast, the mean protein levels of mIL- $1 \beta$ and mIL-18, but not their inactive forms, were significantly increased in the ipsilateral spinal dorsal horn of both genetic groups at $3 \mathrm{~d}$ after nerve injury (Fig. $3 C, D$ ). Of interest, we observed that the increased CatB and mIL- $1 \beta$ were mainly localized in microglia (Fig. $3 E, F$ ), while COX-2 was detected exclusively in neurons (Fig. $3 G$ ), of the ipsilateral spinal dorsal horn of wild-type mice after CFA injection.

Hyperactivation of microglia in the spinal dorsal horn was examined in wild-type and $\mathrm{CatB}^{-1-}$ mice after CFA injection. The morphological changes of microglia in the spinal dorsal horn of the wild-type and $\mathrm{CatB}-/-$ mice were quantitatively analyzed at $3 \mathrm{~d}$ after CFA injection. As shown in Figure $4 A$, CLSM images for Ibal were traced as stack images and then reconstructed as skeletonized images of spinal microglia. These skeletonized images of spinal microglia revealed a significant enlargement of cell bodies (Fig. $4 \mathrm{~B}$ ) and shortening of their processes (Fig. $4 \mathrm{C}$ ) in the ipsilateral spinal dorsal horn of both genetic groups. It was noted that morphological hyperactivation of ipsilateral spinal microglia was significantly lower in $\mathrm{CatB}-/-$ mice than wild-type mice 
(Fig . 4B, C). Furthermore, the mean protein level of Ibal was significantly increased in the ipsilateral spinal dorsal horn of both genetic groups after CFA injection (Fig. $4 D, E$ ), whereas the mean protein level of Iba1 in the ipsilateral dorsal spinal cord of CatB-/- mice was significantly smaller than that of wild-type mice. No pp38-positive microglia were observed in the spinal dorsal horn of either wild-type or $\mathrm{CatB}-/-$ mice (data not shown). At $3 \mathrm{~d}$ after CFA injection, pp38-positive microglia were significantly increased in the spinal dorsal horn of both genetic groups (Fig. $4 F$ ). It was also noted that the mean number of pp38-positive microglia in the spinal dorsal horn of CatB-/- mice (22.0 \pm 4.0 cells $/ 0.04$ $\left.\mathrm{mm}^{2}, n=5\right)$ was significantly smaller than that of wild-type mice $(46.0 \pm 5.6$ cells $/ 0.04 \mathrm{~mm}^{2}, n=5, p<0.01$, Student's $t$ test). Therefore, it is considered that CFA injection induces the hyperactivation of spinal microglia in both genetic groups. It was also noted that the extent of microglial hyperactivation in $\mathrm{CatB}-/-$ mice was significantly lower than that in wildtype mice. Therefore, the CFA-induced production of mIL- $1 \beta$ and $\mathrm{mIL}-18$ by hyperactivated spinal microglia depends on the enzymatic activity of CatB, whereas the nerve injury-induced production of mIL-1 $\beta$ and mIL-18 by hyperactivated spinal microglia is CatBindependent.

CatB is required for the production of mIL-1 $\beta$ and $\mathrm{mIL}-18$ by

CGA-treated microglia

In general, ligands that are associated with phagocytic receptors, such as fibrillar $\mathrm{A} \beta$, use a CatB-dependent pathway for the production of $\mathrm{mIL}-1 \beta$ (Halle et al., 2008). CGA, a neuroactive glycoprotein, is known to be a potent microglial activator (Kingham et al., 1999; Terada et al., 2010) and is significantly elevated in subjects with inflammatory diseases, such as rheumatoid arthritis (Di Comite et al., 2009). ATP and LPA are also known as endogenous microglial activators that are involved in the induction of neuropathic pain (Tsuda et al., 2003; Inoue et al., 2004; Coull et al., 2005; Donnelly-Roberts et al., 2007; Fujita et al., 2008). ATP uses a CatBindependent pathway for the IL- $1 \beta$ production (Halle et al., 2008 ), while no information is available for a requirement of CatB in LPA-induced IL- $1 \beta$ production pathway. In this study, $\mathrm{CatB}$ was found to be necessary for the induction of inflammatory pain but not in neuropathic pain, whereas spinal microglia expressed $\mathrm{mIL}-1 \beta$ in both chronic pain models. These findings suggest that inflammatory and neuropathic pain uses CatBdependent and CatB-independent mechanisms for the mIL- $1 \beta$ prountreated cells).
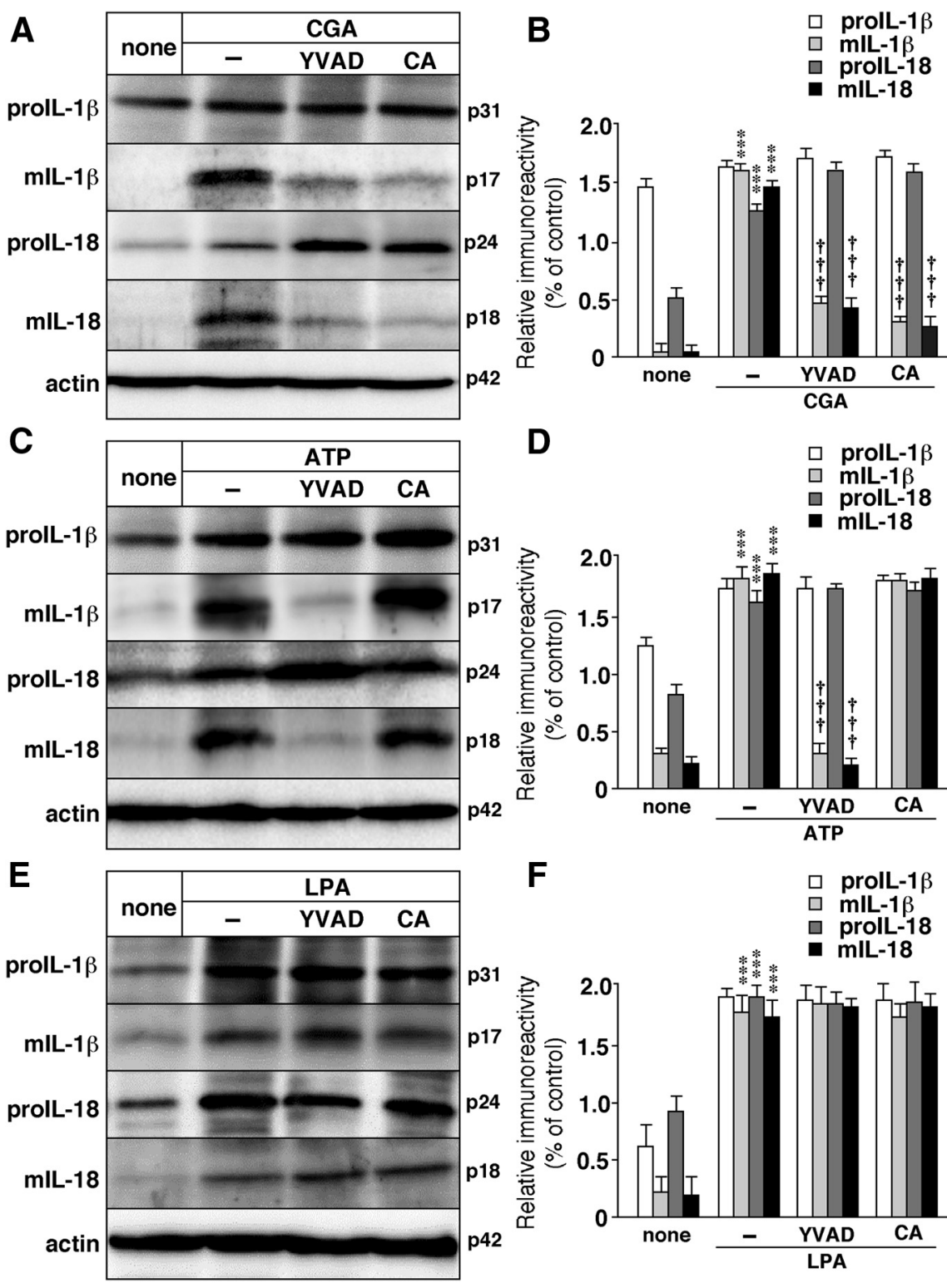

Figure 5. CatB-dependent and CatB-independent mechanisms underlying the production of $\mathrm{mlL}-1 \beta$ and $\mathrm{mlL}-18$ from microglia following treatment with CGA, ATP, and LPA. $A$, The requirement for CatB in the production of $\mathrm{mLL}-1 \beta$ and $\mathrm{mIL}-18$ by MG6 microglia following treatment with CGA (10 nm) for $24 \mathrm{~h}$. z-YVAD-fmk (YVAD, $50 \mu \mathrm{m})$ or CA-074Me (CA, $50 \mu \mathrm{m})$ was applied $2 \mathrm{~h}$ before treatment with CGA. $\boldsymbol{B}$, The quantitative analyses of immunoblots in $\boldsymbol{A}$. Each column and vertical bar represents the means \pm SEM ( $n=3$, each). ${ }^{* * *} p<0.001$, two-way ANOVA test (CGA-treated cells vs untreated cells); ${ }^{\text {ttt }} p<0.001$, two-way ANOVA test (inhibitors, YVAD, or CA, with CGA-treated cells vs CGA-treated cells). C, No requirement for CatB in the production of mIL-1 $\beta$ and mIL-18 by MG6 microglia following treatment with ATP $(5 \mathrm{~mm})$ for $2 \mathrm{~h}$ after priming with LPS (100 $\mathrm{ng} / \mathrm{ml})$ for $1 \mathrm{~h}$. z-YVAD-fmk (YVAD, $50 \mu \mathrm{m})$ or CA-074Me (CA, $50 \mu \mathrm{m})$ was applied $2 \mathrm{~h}$ before treatment with ATP. $D$, The quantitative analyses of immunoblots in C. Each column and vertical bar represents the means $\pm \operatorname{SEM}\left(n=3\right.$, each). ${ }^{* *} p<0.001$, two-way ANOVA test (ATP-treated cells vs untreated cells); ${ }^{t+t} p<0.001$, two-way ANOVA test (YVAD vs ATP-treated cells). $\boldsymbol{E}$, No requirement for CatB in the production of mIL-1 $\beta$ or mIL-18 by MG6 microglia following treatment with LPA (10 $\mu \mathrm{m})$ for $24 \mathrm{~h}$. z-YVAD-fmk (YVAD, 50 $\mu \mathrm{m})$ or $(\mathrm{A}-074 \mathrm{Me}(\mathrm{CA}, 50 \mu \mathrm{m})$ was applied $2 \mathrm{~h}$ before treatment with LPA. $\boldsymbol{F}$, The quantitative analyses of immunoblots in $\boldsymbol{E}$. Each column and vertical bar represents the means \pm SEM $\left(n=3\right.$, each). ${ }^{* * *} p<0.001$, two-way ANOVA test (LPA-treated cells vs

duction in spinal microglia, respectively. To explore causative factors that are involved in hyperactivation of spinal microglia and the subsequent induction of inflammatory pain, we have examined the CatB-dependency for the production of mIL-1 $\beta$ and mIL-18 in microglia by pain-related endogenous microglial activators, including CGA, ATP, and LPA. We found that CA$074 \mathrm{Me}(50 \mu \mathrm{M})$ as well as z-YVAD-fmk $(50 \mu \mathrm{M})$, a specific inhibitor of caspase-1, significantly attenuated the CGA-induced 


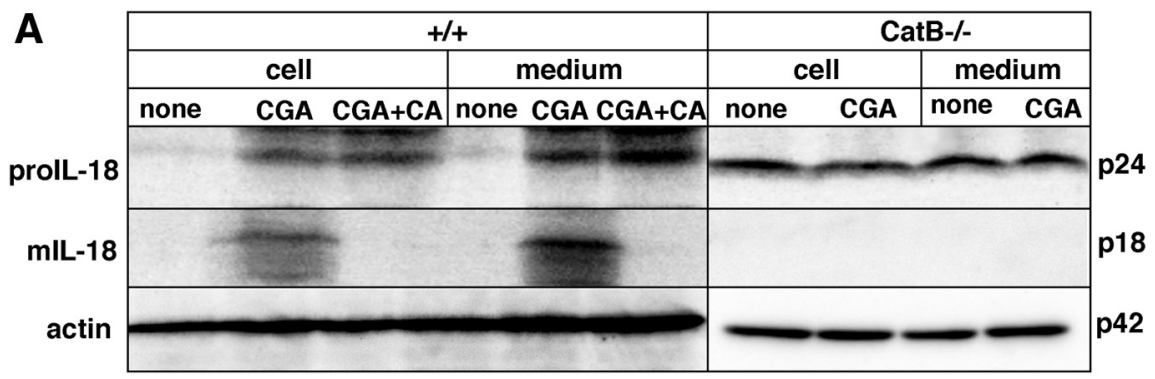

\section{B

$$
\square \text { prolL-18 }
$$$$
\text { - mIL-18 }
$$

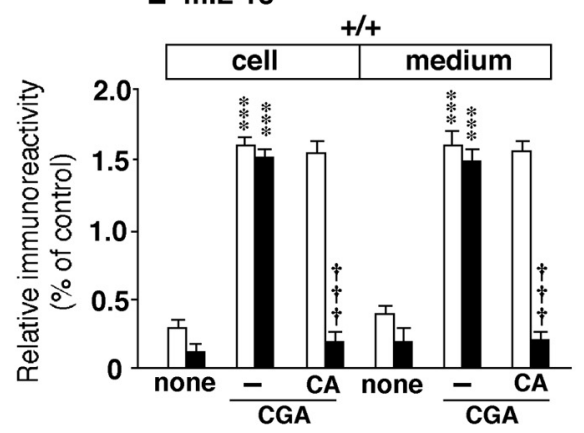

D

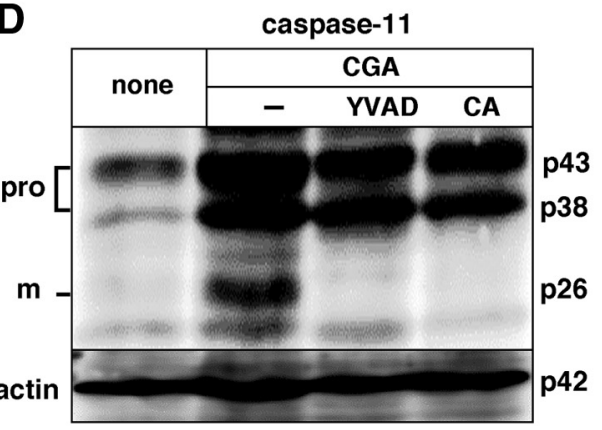

C

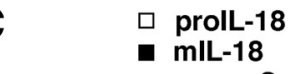

mIL-18

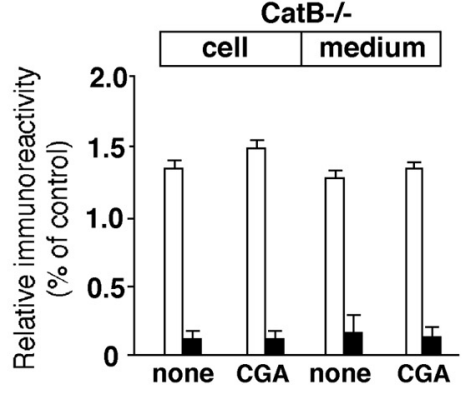

E

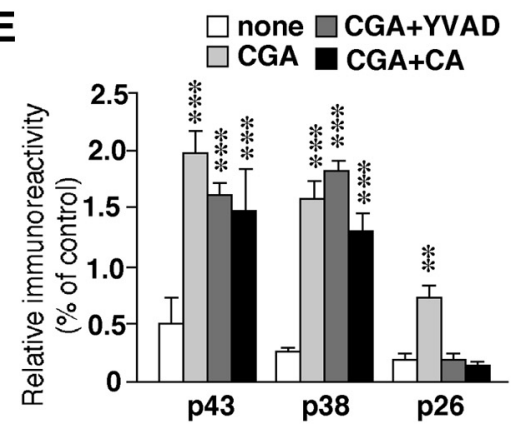

Figure 6. CatB dependent mechanisms underlying the production of mlL-18 from primary cultured microglia following treatment with CGA. $A$, The immunoblots showing mIL-18 in cell lysates and the culture medium of wild-type $(+/+)$ and CatB-/primary cultured microglia after treatment with CGA (10 nm) for $24 \mathrm{~h}$. z-YVAD-fmk (YVAD, $50 \mu \mathrm{m}$ ) or CA-074Me (CA, $50 \mu \mathrm{M})$ was applied $2 \mathrm{~h}$ before treatment with CGA. $\boldsymbol{B}, \boldsymbol{C}$, The quantitative analyses of immunoblots in wild-type $(+/+)$ primary cultured microglia $(\boldsymbol{B})$ and $\mathrm{CatB}-1-$ primary cultured microglia $(\boldsymbol{C})$. Each column and vertical bar represents the means $\pm \operatorname{SEM}(n=3$, each) ${ }^{* * *} p<0.001$, two-way ANOVA test (CGA-treated cells vs untreated cells); ${ }^{\dagger+\dagger} p<0.001$, two-way ANOVA test (CA vs (GA-treated cells). D, Immunoblot showing the proteolytic activation of pro-caspase-11 in MG6 microglia following treatment with CGA (10 nm) for $24 \mathrm{~h}$. z-YVAD-fmk (YVAD, $50 \mu \mathrm{m}$ ) or CA-074Me (CA, $50 \mu \mathrm{m})$ was applied $2 \mathrm{~h}$ before treatment with CGA. $\boldsymbol{E}$, The quantitative analyses of immunoblots in $\boldsymbol{D}$. Each column and vertical bar represents the means $\pm \mathrm{SEM}\left(n=3\right.$, each). ${ }^{* *} p<$ 0.001, two-way ANOVA test (CGA-treated cells vs untreated cells).

production of mIL- $1 \beta$ and $\mathrm{mIL}-18$ without affecting the production of their inactive forms in MG6 microglia (Fig. $5 A, B$ ). In contrast, CA-074Me did not affect either ATP- or LPA-induced production of mIL- $1 \beta$ and mIL-18 in MG6 microglia (Fig. 5C$F)$. On the other hand, z-YVAD-fmk strongly inhibited ATP- or LPA-induced production of both mIL- $1 \beta$ and mIL-18 without affecting the pro-IL-18 production (Fig. $5 C-F$ ). Furthermore, mIL-18 was produced and secreted by CGA-treated primary cultured microglia prepared from wide-type mice (Fig. 6A, C). However, mIL-18 was not produced by CGA-treated primary cultured microglia prepared from $\mathrm{CatB}-/-$ mice (Fig. $6 A, C$ ), which agreed with our previous data showing that there was a specific lack of mIL- $1 \beta$ in CGA-treated primary cultured microglia from CatB-/mice (Terada et al., 2010). Moreover, the proteolytic activation of pro-caspase-11 was induced in MG6 microglia following treatment with CGA (10 nM) (Fig. 6D,E). However, the pro-caspase-11 activa- tion was significantly inhibited by either z-YVAD-fmk (YVAD, $50 \mu \mathrm{M})$ or CA074Me (Fig. 6D,E).

Lysosomal destabilization and the NLRP3 inflammasome are not involved in the GGA-induced IL-1 $\beta$ secretion by microglia

These observations indicate that the CGA-induced production of mIL- $1 \beta$ and mIL-18 by microglia is CatB dependent, whereas their ATP-induced production is $\mathrm{CatB}$ independent. These findings prompted us to investigate how $\mathrm{CatB}$ is involved in the production of mIL- $1 \beta$ and mIL-18 in response to CGA. Some evidence suggested that the leakage of CatB into the cytoplasm was responsible for the activation of the NLRP3 inflammasome, which promotes the proteolytic cleavage of pro-caspase- 1 for the production of mIL-1 $\beta$. Our previous observations, however, indicated that $\mathrm{CatB}$ was localized in LAMP-1-positive enlarged lysosomes, without any sign of its cytosolic leakage in CGA-treated primary cultured microglia (Terada et al., 2010). We therefore examined whether CGA could induce the lysosomal destabilization and leakage of CatB in microglia using two different reagents. One was an acidity-dependent acridine orange, and the other was a cell-permeable fluorescently labeled CatB substrate, z-Arg-Arg-cresyl violet, the fluorescent cresyl violet group of which was designed to be dequenched upon cleavage of one or both of the arginines by CatB. The punctuate acridine orange aggregates were observed in both untreated and CGAtreated MG6 microglia (Fig. 7A). The enzymatic activity of CatB was also visible as punctuate bright signals in MG6 microglia, even after treatment with CGA (Fig. $7 A$ ). On the other hand, Leu-Leu-OMe, which is known to induce lysosomal damage (Thiele and Lipsky, 1985, 1990), markedly reduced the fluorescent signals for both acridine orange and CatB activity in MG6 microglia (Fig. $5 A$ ). We further examined the requirement of the NLRP3 inflammasome during the IL- $1 \beta$ production by CGA-treated MG6 microglia using siRNAs. The expression of the NLRP3 receptor, a crucial component of the NLRP3 inflammasome, was reduced by $77 \%$ in MG6 microglia using a combination of two NLRP3targeted siRNAs (Fig. 7B). We found that silencing the NLRP3 gene did not significantly reduce the IL- $1 \beta$ production by MG6 microglia following treatment with CGA (Fig. $7 C$ ). In contrast, silencing of the NLRP3 gene completely abolished the IL- $1 \beta$ production by MG6 microglia following treatment with ATP (Fig. $7 D)$. These observations clearly demonstrate that the CGAinduced IL- $1 \beta$ production is dependent on $\mathrm{CatB}$, and that it does not result from its leakage into the cytoplasm. However, this function is considered to be independent of the NLRP3 inflammasome. 
The differential dependency on CatB for the production of $\mathrm{mIL}-1 \boldsymbol{\beta}$ by spinal microglia, and the generation of tactile allodynia induced by CGA or ATP

We further investigated whether the intrathecal injection of CGA, ATP, or LPA could mimic the change in the pain threshold and production of mIL- $1 \beta$ by spinal microglia in wild-type and CatB-/- mice after CFA injection or nerve injury. A single intrathecal administration of CGA $(10 \mathrm{~nm}, 5 \mu \mathrm{l})$ caused tactile allodynia in wild-type mice (Fig. $8 \mathrm{~A}-$ $C)$. In contrast, allodynia was significantly attenuated in the CGA-administered CatB $-/-$ mice (Fig. $8 \mathrm{~A}$ ). After intrathecal administration of CGA, the mean protein level of $\mathrm{mIL}-1 \beta$ in the spinal dorsal horn of $\mathrm{CatB}-/-$ mice was significantly lower than that of wild-type mice (Fig. $8 D, E)$. On the other hand, a single intrathecal administration of ATP (100 nM, 5 $\mu \mathrm{l})$ or LPA (100 nM, $5 \mu \mathrm{l})$ induced tactile allodynia in both genetic groups to the similar extent (Fig. 8B,C). Furthermore, there was no significant difference in the mean protein level of mIL- $1 \beta$ in the spinal dorsal horn of wild-type and $\mathrm{CatB}-/-$ mice after intrathecal administration of either ATP or LPA (Fig. 8D,E). Furthermore, mIL- $1 \beta$-positive microglia were hardly detectable in the spinal dorsal horn of CGA-administered CatB-/ - mice. In contrast, many mIL- $1 \beta$-positive microglia were observed in the spinal dorsal horn expression ATP- or LPSadministered $\mathrm{CatB}-/-$ mice (Fig. $8 F$ ).

Therefore, CGA could mimic the CFA injection-induced inflammatory pain, suggesting that CGA may work as the endogenous microglial activator in the spinal dorsal horn after CFA injection.

To examine this possibility, expression of CGA was finally examined in both the spinal dorsal horn and the DRG. To analyze the specificity of anti-CGA antibody used in the present study, immunoblotting analyses of CGA were first conducted. Soluble extracts of the spinal dorsal horn from both genetic groups showed two bands with apparent molecular mass of 75 and 68 $\mathrm{kDa}$, which corresponded to the naive full-length CGA and a major proteolytic product, respectively (Fig. 9A), thus indicating specificity of the immunoreaction of the anti-CGA antibody. No significant difference in the mean level of each protein band was observed between the ipsilateral and contralateral spinal dorsal horn of CFA-injected mice (Fig. 9A,B). In the spinal dorsal horn, immunoreactivity of CGA was occasionally found in the varicose fibers or spherical terminal boutons (data not shown). We further conducted immunohistochemical analyses to elucidate the cellular localization of CGA in DRG, because it is considered that CGA may be secreted from the varicose axons and/or axon terminals of DRG neurons in the spinal dorsal horn. Immunoreactivity for CGA was observed in the perinuclear vesicles in DRG neurons of both genetic groups (Fig. $9 C$, first and third columns). After CFA injection, the mean IF intensity of CGA in DRG neurons of the ipsilateral side was significantly larger than that in the contralateral side of both wild-type mice (ipsilateral: $10.4 \pm 3.7$, contralateral: $4.8 \pm 1.9 ; n=30, p<0.01$, one-way ANOVA) and CatB-/ - mice (ipsilateral: $10.0 \pm 2.6$, contralateral: $4.7 \pm 2.7 ; n=30, p<0.01$, one-way ANOVA) (Fig. 9C, second and fourth columns). The specificity of the immunoreaction of CGA was also tested by omitting the anti-CGA antibody. No specific immunostaining was observed in these sections (data not shown).

\section{Discussion}

We investigated the possible involvement of CatB in the induction of chronic pain, because CatB plays an essential role in the microglial production of mIL- $1 \beta$, which is an accepted painrelated molecule known to be key for both neuropathic and inflammatory pain (Samad et al., 2001; Sweitzer et al., 2001; Kawasaki et al., 2008; Ren and Torres, 2009). We herein showed for the first time that inhibition of CatB activity, either through genetic deletion or via a pharmacological inhibitor significantly reduced the CFA-induced long-lasting tactile allodynia without affecting the CFA-induced paw inflammation. In agreement with the significant reduction of CFA-induced pain hypersensitivity, the production of both $\mathrm{mIL}-1 \beta$ and $\mathrm{mIL}-18$ was significantly reduced in the spinal microglia of $\mathrm{CatB}-/-$ mice, indicating that inflammatory pain is dependent on the production of spinal mIL- $1 \beta$ and mIL-18, as has been suggested in previous studies (Guo et al., 2007; Shan et al., 2007; Verri et al., 2007; Fiorentino et al., 2008). Furthermore, a significant reduction of COX-2 was also observed in the spinal dorsal horn neurons of CFA-injected 

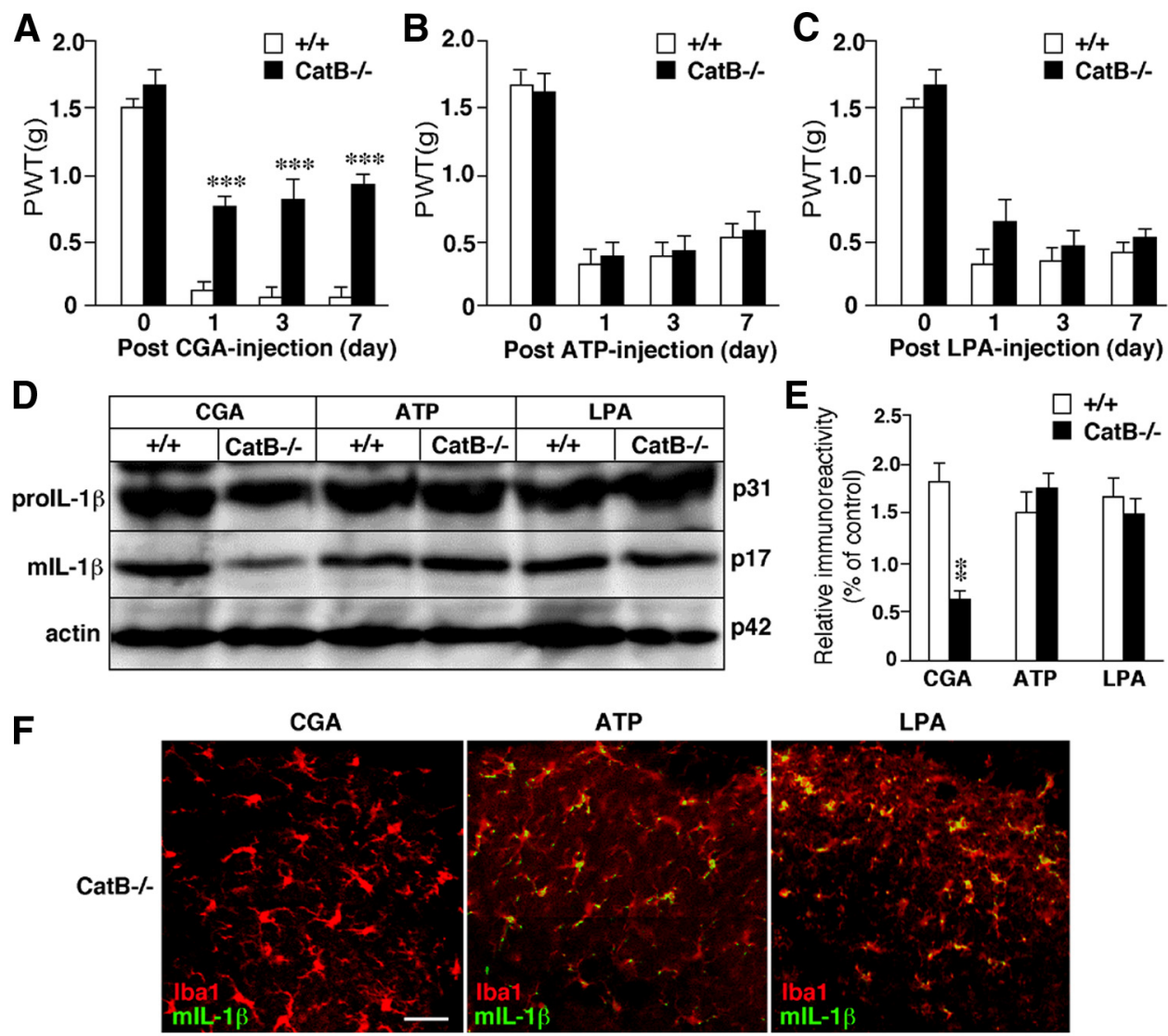

Figure 8. The differential requirements for CatB in the induction of tactile allodynia and the mIL-1 $\beta$ production by spinal microglia following a single intrathecal administration of CGA, ATP, or LPA. $A$, The requirement for CatB in tactile allodynia induced by intrathecal administration of CGA (10 nM, $5 \mu \mathrm{l})$. $\boldsymbol{B}$, No requirement for CatB in tactile allodynia induced by intrathecal administration of ATP $(100 \mathrm{~nm}, 5 \mu \mathrm{l})$. C, No requirement for CatB in the mechanical allodynia induced by intrathecal administration of LPA $(100 \mathrm{~nm}, 5 \mu \mathrm{l})$. Each column and vertical bar represents the means \pm SEM $\left(n=6\right.$, each). ${ }^{* * *} p<0.001$, two-way ANOVA $(+/+$ vs CatB $-/-$ mice). $\boldsymbol{D}$, Immunoblots showing proll-1 $\beta$ expression in the spinal dorsal horn of wild-type $(+/+)$ and CatB $-/-$ mice at $3 \mathrm{~d}$ after intrathecal administration of CGA, ATP, or LPA. $\boldsymbol{E}$, The quantitative analyses of immunoblots in $\boldsymbol{D}$. Each column and vertical bar represents the means \pm SEM of three independent experiments $\left(n=3\right.$, each; two-way ANOVA test, ${ }^{* *} p<0.01,+/+$ vs CatB $-/-$ mice following intrathecal administration of CGA). $\boldsymbol{F}$, The IF CLSM images for Iba 1 (red) and mlL-1 $\beta$ (green) in the spinal dorsal horn of CatB $-1-$ mice at $3 \mathrm{~d}$ after intrathecal administration of CGA, ATP, or LPA. Scale bar, $20 \mu \mathrm{m}$.

CatB $-/-$ mice. This result is considered to be a consequence of the impaired CatB-dependent production of $\mathrm{mIL}-1 \beta$ by spinal microglia in $\mathrm{CatB}-/-$ mice, because IL- $1 \beta$ is a major inducer of COX-2, which augments the processing of nociceptive stimuli through the production of $\mathrm{PGE}_{2}$ during inflammatory pain (Samad et al., 2001; Lee et al., 2004; Vardeh et al., 2009). Therefore, it may be concluded that microglial CatB has an essential role in the induction and maintenance of the CFA-induced inflammatory pain.

It has been considered that the microglial hyperactivation is involved in CFA-induced pain hypersensitivity, because treatment with minocycline completely prevented the development of CFA-induced allodynia (Shan et al., 2007). However, little information has been available about the endogenous activators of microglia in the spinal cord during inflammatory pain. CGA, a neuroactive glycoprotein, is known to be a potent endogenous microglial activator (Kingham et al., 1999). CGA is released, together with the costored hormones and peptides, in the extracellular environment and then in circulation. It is also known that the circulating CGA level is upregulated in subjects with chronic inflammatory pain diseases, such as rheumatoid arthritis (Di Comite et al., 2009). Furthermore, we have previously reported that CGA markedly induced the production of pro-CatB and its subsequent proteolytic maturation in cultured microglia (Terada et al., 2010). In the present study, immunoreactivity for CGA was found in the perinuclear vesicles of DRG neurons. Immunoblot analyses showed relative strong bands corresponding to CGA observed in the spinal dorsal horn, whereas immunoreactivity for CGA was only occasionally observed in varicose fibers or spherical terminal boutons. Furthermore, the mean IF intensity of CGA in DRG neurons was significantly increased in both genetic groups after CFA injection. More important, a single intrathecal injection of CGA induced long-lasting tactile allodynia and the production of mIL- $\beta$ by spinal microglia. These observations strongly suggest that CGA is a candidate activator of microglia, which is responsible for the induction of inflammatory pain.

The activation of caspase- 1 in the spinal cord was demonstrated to cause an increase in the IL- $1 \beta$ production and thereby to promote COX-2-dependent inflammatory hypernociception (Lee et al., 2004). Our present and previous (Terada et al., 2010) studies demonstrated that CGA activates microglia to release the mature forms of IL- $1 \beta$ and IL- 18 in a CatB-dependent manner. A specific inhibitor of caspase-1, z-YVAD-fmk, significantly attenuated the production of both mIL- $1 \beta$ and mIL-18 following treatment with CGA, thus indicating that caspase- 1 is necessary for their CGA-induced production by microglia. Although caspase-1 is an intracellular enzyme that is essential for the maturation of the inactive forms of IL- $1 \beta$ and IL-18 (Dinarello 1998; Fantuzzi and Dinarello, 1999), the mechanism underlying the activation of pro-caspase- 1 is still a matter of controversy. Re- 

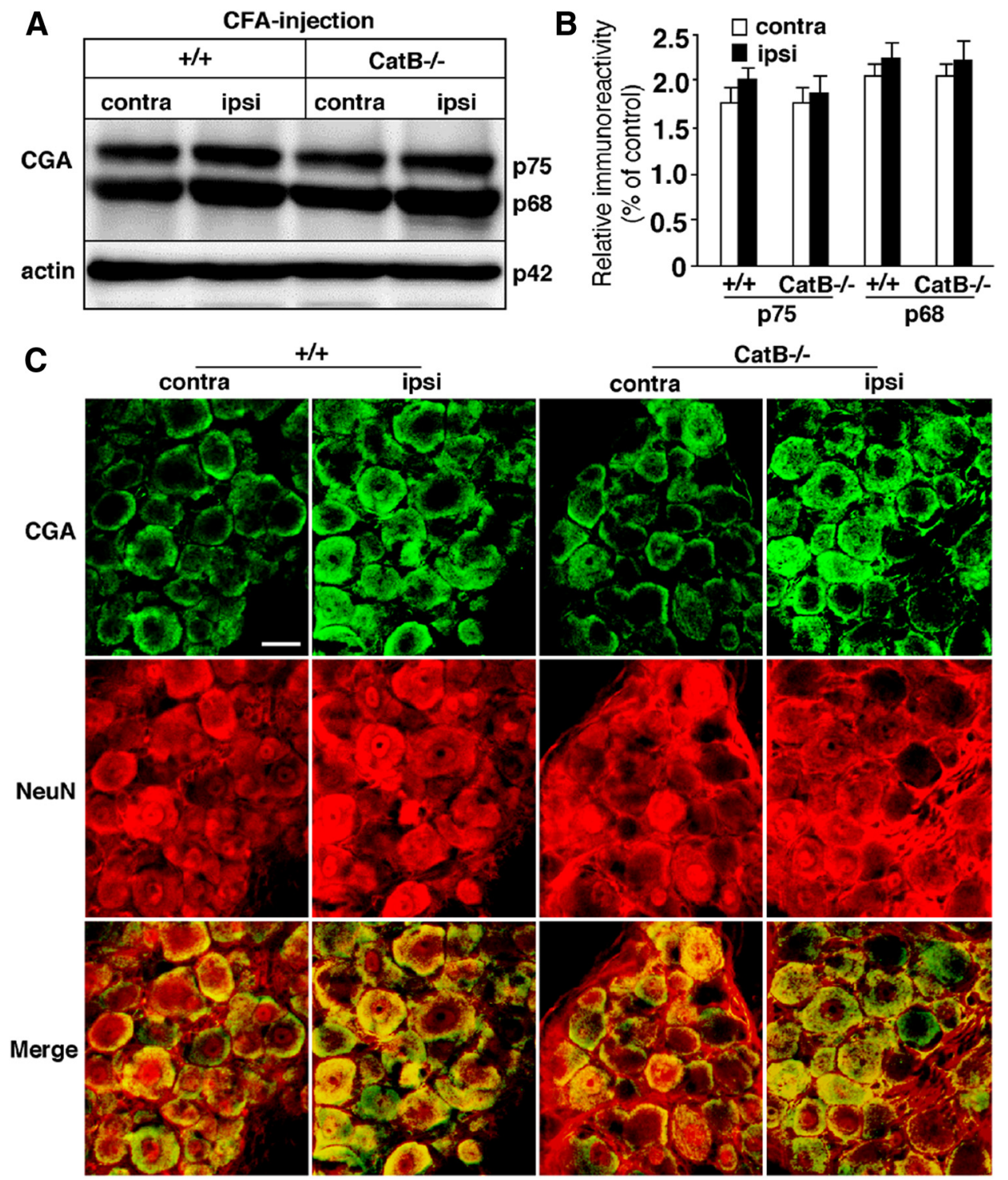

Figure 9. The expression of CGA in the DRG and the spinal dorsal horn during (FA-induced pain hypersensitivity. $A$, Immunoblot showing the CGA expression in the spinal dorsal horn of wild-type $(+/+)$ and CatB $-/-$ mice at $3 \mathrm{~d}$ after CFA injection. $\boldsymbol{B}$, The quantitative analyses of immunoblots in $A$. Each column and vertical bar represents the means $\pm S E M(n=3$, each). $C$, The IF CLSM images for NeuN (red) and CGA (green) in the DRG of $+/+$ and CatB $-/$ - mice at $3 \mathrm{~d}$ after CFA injection. Scale bar, $20 \mu \mathrm{m}$.

cently, fibrillar $\mathrm{A} \beta$, silica, and cholesterol crystals have been reported to induce lysosomal destabilization, which causes CatB leakage into the cytoplasm in macrophages and microglia (Halle et al., 2008; Hornung et al., 2008; Duewell et al., 2010). The cytosolic leakage of CatB in turn leads to the proteolytic cleavage of an unidentified substrate, which activates the NLRP3 inflammasomes (Halle et al., 2008; Stutz et al., 2009; Tschopp and Schroder, 2010). In the current study, CGA was not found to induce the lysosomal destabilization or CatB leakage into the cytoplasm in microglia. Furthermore, the silencing of the NLRP3 gene did not affect the IL- $1 \beta$ production by microglia following treatment with CGA. Therefore, the activation of pro-caspase-1 in microglia following treatment with CGA depends on neither the cytosolic leakage of CatB nor the subsequent activation of NLRP3 inflammasomes.

We have previously reported that immunoreactivities for ml- $1 \beta$ and caspase- 1 were colocalized in CatB-containing enlarged lysosomes (Terada et al., 2010). These CatB-containing enlarged lysosomes are considered to be phagolysosomes formed by the fusion between scavenger receptor class-A (SR-A)mediated phagosomes and primary lysosomes, because CGA is reported to activate microglia through binding to SR-A (Hooper et al., 2009). Therefore, the inactive forms of caspase-1, IL- $1 \beta$, and IL-18 in the cytoplasm may be trapped in the CatBcontaining phagolysosome during their formation triggered by CGA. There have been some reports suggesting that CatB is directly associated with the proteolytic cleavage of pro-caspase- 1 in the endosomal/lysosomal system. Although CatB can efficiently cleave pro-caspase-11 in a cell-free system even at neutral $\mathrm{pH}$, it cleaves pro-caspase- 1 only at an acidic $\mathrm{pH}$ (Vancompernolle et al., 1998). Furthermore, CatB was directly involved in the proteolytic cleavage of pro-casapase-1 in THP-1 monocytic cells after stimulation with the microbial toxin, nigericin (Hentze et al., 2003). However, the sizes of the cleaved fragments of procaspase-1 generated by CatB digestion (37 and $40 \mathrm{kDa}$ ) are different from the active fragments that are produced by caspase- 1 self-processing $(10$ and $20 \mathrm{kDa})$. It is possible that the fragments of pro-caspase-1 resulting from the cleavage by CatB may be 
further cleaved to the active fragments by self-processing. It should also be considered whether CatB is indirectly involved in the activation of pro-caspase- 1 though its direct activation of pro-caspase-11, because caspase- 11 is known to play a crucial role in the activation of pro-caspase-1 (Schotte et al., 1998; Kang et al., 2000). Moreover, we previously demonstrated that CatB and caspase- 1 were colocalized, and that CA-074Me markedly inhibited the caspase-1 expression in CGA-stimulated microglia (Terada et al., 2010) indicating that CatB might be directly involved in caspase- 1 activation. Together, these findings indicate that CatB is responsible for the CGA-induced proteolytic processing of pro-casapase- 1 to its mature form in the phagolysosomes of microglia, which contain inactive forms of IL- $1 \beta$ and IL-18. However, a possibility that CatB is indirectly involved in the activation of caspase- 1 through the proteolytic maturation of caspase-11 cannot be totally ruled out, because CA-074Me also significantly inhibited the expression of caspase-11 in CGAstimulated microglia in the present study.

Surprisingly, CatB deficiency had no effect on nerve injuryinduced neuropathic pain, despite the fact that the production of mIL- $1 \beta$ by spinal microglia also plays a pivotal role in the induction of neuropathic pain. In the present study, CatB was also increased in the spinal dorsal horn of nerve-injured mice to a similar degree as that observed in the CFA-injected mice. The mature forms of IL- $1 \beta$ and IL-18 were also induced in the nerveinjured mice, confirming that neuropathic pain is also dependent on spinal mIL-1 $\beta$ and mIL-18 (Scholz and Woolf, 2007; Kawasaki et al., 2008; Miyoshi et al., 2008). However, the nerve injuryinduced production of both mIL- $1 \beta$ and mIL-18 in the spinal dorsal horn was not affected by CatB deficiency. ATP is accepted as a major mediator of neuropathic pain, because the extracellular ATP levels are elevated in the DRGs (Matsuka et al., 2008; Kanno et al., 2010) and numerous of ATP receptors, including $\mathrm{P}_{2} \mathrm{X}_{4}, \mathrm{P}_{2} \mathrm{X}_{7}$, and $\mathrm{P} 2 \mathrm{Y}_{12}$, are activated in microglia to mediate neuropathic pain (Tsuda et al., 2003; Guo et al., 2007; Jarvis, 2010). Interestingly, intrathecal injection of ATP-activated microglia in the spinal cord is sufficient to induce allodynia (Tsuda et al., 2003). Our observations indicated that z-YVAD-fmk, but not CA-074Me, significantly attenuated the ATP-induced production of mIL-1 $\beta$ and mIL-18, and that the silencing of the NLRP3 gene significantly attenuated the production of mIL-1 $\beta$ by ATP-treated microglia, providing further evidence that the NLRP3 inflammasome is essential for the ATP-induced caspase1 -dependent production of mIL- $1 \beta$ and mIL-18 (Mariathasan et al., 2006). Furthermore, a single intrathecal ATP injection induced allodynia and increased the production of mIL- $\beta$ by spinal microglia in both wild-type and CatB $-/-$ mice. However, it has been reported that caspase- 1 is not necessary for the nerve injuryinduced production of mIL- $1 \beta$ in spinal microglia (Kawasaki et al., 2008). These observations strongly suggest that ATP is not a primary trigger of mIL- $\beta$ secretion from spinal microglia after nerve injury, because the enzymatic activity of caspase- 1 is necessary for the ATP-induced production of mIL-1 $\beta$ by cultured microglia.

Chronic pain, including arthritis pain, is an increasing burden for the society, and affects an estimated $20 \%$ of the population (Suter et al., 2007). Inflammatory pain is generally treated with nonsteroidal anti-inflammatory drugs (NSAIDs), COX-2 inhibitors, and opioids, but all of these treatments are limited due to the occurrence of side effects. Opioids cause respiratory depression, constipation, dependence, tolerance, and addiction, and there are serious cardiovascular effects associated with the longterm use of COX-2 inhibitors (Funk and FitzGerald, 2007).
NSAIDs increase the risk of heart failure and enteropathy especially in the elderly, thus further increasing the healthcare costs in the older population (Mangoni et al., 2010; Triantafyllou et al., 2010). The observed role of CatB in inflammatory pain suggests that CatB-specific inhibitors may represent a useful new strategy for treating inflammation-associated pain, such as arthritic pain and postoperative pain.

\section{References}

Broom DC, Samad TA, Kohno T, Tegeder I, Geisslinger G, Woolf CJ (2004) Cyclooxygenase 2 expression in the spared nerve injury model of neuropathic pain. Neuroscience 124:891-900.

Cardona A, Saalfeld S, Arganda I, Pereanu W, Schindelin J, Hartenstein V (2010) Identifying neuronal lineages of Drosophila by sequence analysis of axon tracts. J Neurosci 30:7538-7553.

Chaplan SR, Bach FW, Pogrel JW, Chung JM, Yaksh TL (1994) Quantitative assessment of tactile allodynia in the rat paw. J Neurosci Methods 53:55-63.

Coull JA, Beggs S, Boudreau D, Boivin D, Tsuda M, Inoue K, Gravel C, Salter MW, De Koninck Y (2005) BDNF from microglia causes the shift in neuronal anion gradient underlying neuropathic pain. Nature 438:1017-1021.

Di Comite G, Rossi CM, Marinosci A, Lolmede K, Baldissera E, Aiello P, Mueller RB, Herrmann M, Voll RE, Rovere-Querini P, Sabbadini MG, Corti A, Manfredi AA (2009) Circulating chromogranin A reveals extraarticular involvement in patients with rheumatoid arthritis and curbs TNF- $\alpha$-elicited endothelial activation. J Leukoc Biol 85:81-87.

Dinarello CA (1998) Interleukin-1 $\beta$, interleukin-18, and the interleukin-1 $\beta$ converting enzyme. Ann N Y Acad Sci 856:1-11.

Donnelly-Roberts DL, Jarvis MF (2007) Discovery of $\mathrm{P}_{2} \mathrm{X}_{7}$ receptorselective antagonists offers new insights into $\mathrm{P} 2 \mathrm{X}_{7}$ receptor function and indicates a role in chronic pain states. Br J Pharmacol 151:571-579.

Duewell P, Kono H, Rayner KJ, Sirois CM, Vladimer G, Bauernfeind FG, Abela GS, Franchi L, Nuñez G, Schnurr M, Espevik T, Lien E, Fitzgerald KA, Rock KL, Moore KJ, Wright SD, Hornung V, Latz E (2010) NLRP3 inflammasomes are required for atherogenesis and activated by cholesterol crystals. Nature 464:1357-1361.

Fantuzzi G, Dinarello CA (1999) Interleukin-18 and interleukin-1 $\beta$ : two cytokine substrates for ICE (caspase-1). J Clin Immunol 19:1-11.

Fiorentino PM, Tallents RH, Miller JN, Brouxhon SM, O'Banion MK, Puzas JE, Kyrkanides S (2008) Spinal interleukin- $1 \beta$ in a mouse model of arthritis and joint pain. Arthritis Rheum 58:3100-3109.

Fujita R, Ma Y, Ueda H (2008) Lysophosphatidic acid-induced membrane ruffling and brain-derived neurotrophic factor gene expression are mediated by ATP release in primary microglia. J Neurochem 107:152-160.

Funk CD, FitzGerald GA (2007) COX-2 inhibitors and cardiovascular risk. J Cardiovasc Pharmacol 50:470-479.

Guo W, Wang H, Watanabe M, Shimizu K, Zou S, LaGraize SC, Wei F, Dubner R, Ren K (2007) Glial-cytokine-neuronal interactions underlying the mechanisms of persistent pain. J Neurosci 27:6006-6018.

Halle A, Hornung V, Petzold GC, Stewart CR, Monks BG, Reinheckel T, Fitzgerald KA, Latz E, Moore KJ, Golenbock DT (2008) The NALP3 inflammasome is involved in the innate immune response to amyloid- $\beta$. Nat Immunol 9:857-865.

Hargreaves K, Dubner R, Brown F, Flores C, Joris J (1988) A new and sensitive method for measuring thermal nociception in cutaneous hyperalgesia. Pain 32:77-88.

Hayashi Y, Yoshida M, Yamato M, Ide T, Wu Z, Ochi-Shindou M, Kanki T, Kang D, Sunagawa K, Tsutsui H, Nakanishi H (2008) Reverse of agedependent memory impairment and mitochondrial DNA damage in microglia by an overexpression of human mitochondrial transcription factor A in mice. J Neurosci 28:8624-8634.

Hayashi Y, Kawaji K, Sun L, Zhang X, Koyano K, Yokoyama T, Kohsaka S, Inoue $\mathrm{K}$, Nakanishi $\mathrm{H}$ (2011) $\mathrm{Ca}^{2+}$-activated $\mathrm{K}^{+}$channels are possible molecular targets for the analgesic effects of $S$-ketamine on neuropathic pain. J Neurosci 31:17370-17382.

Hentze H, Lin XY, Choi MS, Porter AG (2003) Critical role for cathepsin B in mediating caspase-1-dependent interleukin-18 maturation and caspase-1- independent necrosis triggered by the microbial toxin nigericin. Cell Death Differ 10:956-968.

Hooper C, Fry VA, Sevastou IG, Pocock JM (2009) Scavenger receptor con- 
trol of chromogranin A-induced microglial stress and neurotoxic cascades. FEBS Lett 583:3461-3466.

Hornung V, Bauernfeind F, Halle A, Samstad EO, Kono H, Rock KL, Fitzgerald KA, Latz E (2008) Silica crystals and aluminum salts activate the NALP3 inflammasome through phagosomal destabilization. Nat Immunol 9:847-856.

Hua XY, Svensson CI, Matsui T, Fitzsimmons B, Yaksh TL, Webb M (2005) Intrathecal minocycline attenuates peripheral inflammation-induced hyperalgesia by inhibiting p38 MAPK in spinal microglia. Eur J Neurosci 22:2431-2440.

Inoue M, Rashid MH, Fujita R, Contos JJ, Chun J, Ueda H (2004) Initiation of neuropathic pain requires lysophosphatidic acid receptor signaling. Nat Med 10:712-718.

Jarvis MF (2010) The neural-glial purinergic receptor ensemble in chronic pain states. Trends Neurosci 33:48-57.

Kang SJ, Wang S, Hara H, Peterson EP, Namura S, Amin-Hanjani S, Huang Z, Srinivasan A, Tomaselli KJ, Thornberry NA, Moskowitz MA, Yuan J (2000) Dual role of caspase-11 in mediating activation of caspase-1 and caspase-3 under pathological conditions. J Cell Biol 149:613-622.

Kanno T, Yaguchi T, Nishizaki T (2010) Noradrenaline stimulates ATP release from DRG neurons by targeting $\beta_{3}$ adrenoceptors as a factor of neuropathic pain. J Cell Physiol 224:345-351.

Kawasaki Y, Xu ZZ, Wang X, Park JY, Zhuang ZY, Tan PH, Gao YJ, Roy K, Corfas G, Lo EH, Ji RR (2008) Distinct roles of matrix metalloproteases in the early- and late-phase development of neuropathic pain. Nat Med 14:331-336.

Kingham PJ, Cuzner ML, Pocock JM (1999) Apoptotic pathway mobilized in microglia and neurones as a consequence of chromogranin A-induced microglial activation. J Neurochem 73:538-547.

Koike M, Shibata M, Ohsawa Y, Nakanishi H, Koga T, Kametaka S, Waguri S, Momoi T, Kominami E, Peters C, Figura K, Saftig P, Uchiyama Y (2003) Involvement of two different cell death pathways in retinal atrophy of cathepsin D-deficient mice. Mol Cell Neurosci 22:146-1461.

Lee KM, Kang BS, Lee HL, Son SJ, Hwang SH, Kim DS, Park JS, Cho HJ (2004) Spinal NF- $\kappa$ B activation induces COX-2 upregulation and contributes to inflammatory pain hypersensitivity. Eur J Neurosci 19:3375-3381.

Mangoni AA, Woodman RJ, Gaganis P, Gilbert AL, Knights KM (2010) Use of non-steroidal anti-inflammatory drugs and risk of incident myocardial infarction and heart failure, and all-cause mortality in the Australian veteran community. Br J Clin Pharmacol 69:689-700.

Mariathasan S, Weiss DS, Newton K, McBride J, O’Rourke K, Roose-Girma M, Lee WP, Weinrauch Y, Monack DM, Dixit VM (2006) Cryopyrin activates the inflammasome in response to toxins and ATP. Nature 440:228-232.

Matsuka Y, Ono T, Iwase H, Mitrirattanakul S, Omoto KS, Cho T, Lam YY, Snyder B, Spigelman I (2008) Altered ATP release and metabolism in dorsal root ganglia of neuropathic rats. Mol Pain 4:66.

Miyoshi K, Obata K, Kondo T, Okamura H, Noguchi K (2008) Interleukin-18-mediated microglia/astrocyte interaction in the spinal cord enhances neuropathic pain processing after nerve injury. J Neurosci 28:12775-12787.

Nakamichi K, Saiki M, Kitani H, Kuboyama Y, Morimoto K, Takayama-Ito M, Kurane I (2006) Suppressive effect of simvastatin on interferon- $\beta$ induced expression of CC chemokine ligand 5 in microglia. Neurosci Lett 407:205-210.

Raghavendra V, Tanga FY, DeLeo JA (2004) Complete Freunds adjuvantinduced peripheral inflammation evokes glial activation and proinflammatory cytokine expression in the CNS. Eur J Neurosci 20:467-473.

Ren K, Torres R (2009) Role of interleukin- $1 \beta$ during pain and inflammation. Brain Res Rev 60:57-64.

Rigaud M, Gemes G, Barabas ME, Chernoff DI, Abram SE, Stucky CL, Hogan QH (2008) Species and strain differences in rodent sciatic nerve anatomy: implications for studies of neuropathic pain. Pain 136:188-201.

Samad TA, Moore KA, Sapirstein A, Billet S, Allchorne A, Poole S, Bonventre JV, Woolf CJ (2001) Interleukin- $1 \beta$-mediated induction of COX-2 in the CNS contributes to inflammatory pain hypersensitivity. Nature 410:471-475.

Sastradipura DF, Nakanishi H, Tsukuba T, Nishishita K, Sakai H, Kato Y, Gotow T, Uchiyama Y, Yamamoto K (1998) Identification of cellular compartments involved in processing of cathepsin $\mathrm{E}$ in primary cultures of rat microglia. J Neurochem 70:2045-2056.

Scholz J, Woolf CJ (2007) The neuropathic pain triad: Neurons, immune cells and glia. Nat Neurosci 10:1361-1368.

Schotte P, Van Criekinge W, Van de Craen M, Van Loo G, Desmedt M, Grooten J, Cornelissen M, De Ridder L, Vandekerckhove J, Fiers W, Vandenabeele P, Beyaert R (1998) Cathepsin B-mediated activation of the proinflammatory caspase-11. Biochem Biophys Res Commun 251:379-387.

Shan S, Qi-Liang MY, Hong C, Tingting L, Mei H, Haili P, Yan-Qing W, Zhi-Qi Z, Yu-Qiu Z (2007) Is functional state of spinal microglia involved in the anti-allodynic and anti-hyperalgesic effects of electroacupuncture in rat model of monoarthritis? Neurobiol Dis 26:558-568.

Stutz A, Golenbock DT, Latz E (2009) Inflammasomes: too big to miss. J Clin Invest 119:3502-3511.

Sun L, Wu Z, Baba M, Peters C, Uchiyama Y, Nakanishi H (2010) Cathepsin B-dependent motor neuron death after nerve injury in the adult mouse. Biochem Biophys Res Commun 399:391-395.

Suter MR, Wen YR, Decosterd I, Ji RR (2007) Do glial cells control pain? Neuron Glia Biol 3:255-268.

Svensson CI, Marsala M, Westerlund A, Calcutt NA, Campana WM, Freshwater JD, Catalano R, Feng Y, Protter AA, Scott B, Yaksh TL (2003) Activation of p38 mitogen-activated protein kinase in spinal microglia is a critical link in inflammation-induced spinal pain processing. J Neurochem 86:1534-1544.

Sweitzer S, Martin D, DeLeo JA (2001) Intrathecal interleukin-1 receptor antagonist in combination with soluble tumor necrosis factor receptor exhibits an anti-allodynic action in a rat model of neuropathic pain. Neuroscience 103:529-539.

Takenouchi T, Ogihara K, Sato M, Kitani H (2005) Inhibitory effects of $\mathrm{U} 73122$ and $\mathrm{U} 73343$ on $\mathrm{Ca}^{2+}$ influx and pore formation induced by the activation of $\mathrm{P} 2 \mathrm{X}_{7}$ nucleotide receptors on mouse microglial cell line. Biochim Biophys Acta 1726:177-186.

Terada K, Yamada J, Hayashi Y, Wu Z, Uchiyama Y, Peters C, Nakanishi H (2010) Involvement of cathepsin $B$ in the processing and secretion of interleukin-1 $\beta$ in chromogranin A-stimulated microglia. Glia 58:114-124.

Thiele DL, Lipsky PE (1985) Regulation of cellular function by products of lysosomal enzyme activity: elimination of human natural killer cells by a dipeptide methyl ester generated from L-leucine methyl ester by monocytes or polymorphonuclear leukocytes. Proc Natl Acad Sci U SA 82:2468-2472.

Thiele DL, Lipsky PE (1990) Mechanism of L-leucyl-L-leucine methyl estermediated killing of cytotoxic lymphocytes: dependence on a lysosomal thiol protease, dipeptidyl peptidase I, that is enriched in these cells. Proc Natl Acad Sci U S A 87:83-87.

Triantafyllou K, Vlachogiannakos J, Ladas SD (2010) Gastrointestinal and liver side effects of drugs in elderly patients. Best Pract Res Clin Gastroenterol 24:203-215.

Tschopp J, Schroder K (2010) NLRP3 inflammasome activation: the convergence of multiple signaling pathways on ROS production? Nat Rev Immunol 10:210-215.

Tsuda M, Shigemoto-Mogami Y, Koizumi S, Mizokoshi A, Kohsaka S, Salter

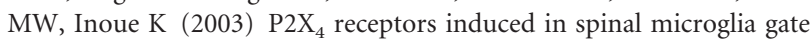
tactile allodynia after nerve injury. Nature 424:778-783.

Tsuda M, Inoue K, Salter MW (2005) Neuropathic pain and spinal microglia: a big program from molecules in "small" glia. Trends Neurosci 28:101-107.

Vancompernolle K, Van Herreweghe F, Pynaert G, Van de Craen M, De Vos K, Totty N, Sterling A, Fiers W, Vandenabeele P, Grooten J (1998) Atractyloside-induced release of cathepsin B, a protease with caspaseprocessing activity. FEBS Lett 438:150-158.

Vardeh D, Wang D, Costigan M, Lazarus M, Saper CB, Woolf CJ, Fitzgerald GA, Samad TA (2009) COX2 in CNS neural cells mediates mechanical inflammatory pain hypersensitivity in mice. J Clin Invest 119:287-294.

Verri WA Jr, Cunha TM, Parada CA, Poole S, Liew FY, Ferreira SH, Cunha FQ (2007) Antigen-induced inflammatory mechanical hypernociception in mice is mediated by IL-18. Brain Behav Immun 21:535-543.

Watkins LR, Milligan ED, Maier SF (2001) Glial activation: a driving force for pathological pain. Trends Neurosci 24:450-455. 